\title{
Review Article \\ Regulating Rac in the Nervous System: Molecular Function and Disease Implication of Rac GEFs and GAPs
}

\author{
Yanyang Bai, Xiaoliang Xiang, Chunmei Liang, and Lei Shi \\ JNU-HKUST Joint Laboratory for Neuroscience and Innovative Drug Research, Jinan University, Guangzhou, \\ Guangdong 510632, China \\ Correspondence should be addressed to Lei Shi; sophielshi80@gmail.com
}

Received 23 January 2015; Accepted 6 March 2015

Academic Editor: Akito Tanoue

Copyright (C) 2015 Yanyang Bai et al. This is an open access article distributed under the Creative Commons Attribution License, which permits unrestricted use, distribution, and reproduction in any medium, provided the original work is properly cited.

\begin{abstract}
Rho family GTPases, including RhoA, Racl, and Cdc42 as the most studied members, are master regulators of actin cytoskeletal organization. Rho GTPases control various aspects of the nervous system and are associated with a number of neuropsychiatric and neurodegenerative diseases. The activity of Rho GTPases is controlled by two families of regulators, guanine nucleotide exchange factors (GEFs) as the activators and GTPase-activating proteins (GAPs) as the inhibitors. Through coordinated regulation by GEFs and GAPs, Rho GTPases act as converging signaling molecules that convey different upstream signals in the nervous system. So far, more than 70 members of either GEFs or GAPs of Rho GTPases have been identified in mammals, but only a small subset of them have well-known functions. Thus, characterization of important GEFs and GAPs in the nervous system is crucial for the understanding of spatiotemporal dynamics of Rho GTPase activity in different neuronal functions. In this review, we summarize the current understanding of GEFs and GAPs for Racl, with emphasis on the molecular function and disease implication of these regulators in the nervous system.
\end{abstract}

\section{Introduction}

Rho family GTPases constitute a distinct family of guanine nucleotide-binding proteins which belongs to the superfamily of Ras-related GTPases. Rho GTPases are key regulators of the actin cytoskeletal dynamics, play crucial roles in various aspects of brain development, and are implicated in a number of neuropsychiatric and neurodegenerative diseases [1-5]. More than 20 mammalian members of Rho family GTPases have been described, including Rho-like (RhoA, RhoB, and RhoC), Rac-like (Racl, Rac2, Rac3, and RhoG), Cdc42-like (Cdc42, TC10/RhoQ, TCL/RhoJ, Wrchl/RhoU, and Chp/ Wrch2/RhoV), Rnd (Rnd1, Rnd2, and Rnd3/RhoE), RhoBTB (Rho-BTB1 and RhoBTB2), RhoD, Rif/RhoF, and RhoH/ TTF $[6,7]$. Like all GTP-binding proteins, Rho GTPases contain sequence motifs for binding to GDP or GTP, thus acting as bimolecular switches, cycling between an inactive GDPbound state and an active GTP-bound state. Activity of Rho GTPases is tightly controlled by the coordinated action of two classes of regulatory proteins: guanine nucleotide exchange factors (GEFs), which activate Rho GTPases by catalyzing the exchange of bound GDP for GTP, enabling them to recognize and activate downstream effectors, and GTPase-activating proteins (GAPs), which suppress Rho GTPases by enhancing their intrinsic rate of GTP hydrolysis to GDP.

Two types of GEFs for Rho GTPases have been identified. Dbl- (diffuse B-cell lymphoma-) like GEFs, the classical GEFs, are characterized by the presence of a DH (Dbl homology) domain followed by a $\mathrm{PH}$ (pleckstrin homology) domain [8]. The DH domain is known to be responsible for the catalytic exchange activity of Rho GEFs, whereas the PH domain regulates lipid binding and membrane targeting. Another type of GEFs is the Dock (dedicator of cytokinesis) family atypical GEFs, which contains a Dock homology region (DHR) 1-DHR2 module instead of the PH-DH module. DHR1-DHR2 module plays similar roles as PH-DH module, of which DHR1 is important for the phospholipid-binding and membrane targeting of Docks, and DHR2 is responsible for its GEF activity [9]. On the other hand, Rho GAPs are usually large multidomain proteins characterized by the presence of a conserved Rho GAP domain and various function domains [10]. A variety of GEFs and GAPs have been 
identified to govern the activity of Rho GTPases in neuronal development and to be associated with neurological diseases $[5,11-13]$.

Racl is one of the most well-studied Rho GTPases which controls a wide range of cellular events of neuronal morphogenesis and motility [14]. Racl is a master protein that directs actin polymerization and cytoskeletal changes through activating a series of signaling pathways, thus acting as a converging sensor molecule that conveys divergent upstream signals. To understand the spatiotemporally dynamic regulation of Racl activity in the nervous system, this review summarizes the current findings of more than 30 Rac GEFs (including both the Dbl-like and atypical GEFs) and GAPs (Table 1). Both the molecular functions and the disease relevance of these regulators in the nervous system will be discussed. Most of these Rac GEFs or GAPs also act on other Rho GTPases (such as RhoA or Cdc42) or even other subfamilies of Ras-related GTPases (such as Ras and Rab). For these regulators, we will emphasize their actions on Rac and will try to discuss how their actions on Rac or other GTPases are differentially regulated.

\section{Dbl-Like Rac GEFs}

2.1. Tiam. Tiaml (T-lymphoma invasion and metastasis 1 ) is one of the most extensively studied Rac GEFs in nervous and other systems. Tiaml is a well-known regulator for synapse formation and plasticity. Tiaml interacts with both EphB receptors and the synaptic neurotransmitter receptors, Nmethyl-D-aspartate (NMDA) receptors, at the postsynaptic sites $[15,16]$. The Rac GEF activity of Tiaml is upregulated by CaMKII $\left(\mathrm{Ca}^{2+} /\right.$ Calmodulin-dependent protein kinase II) dependent phosphorylation and EphB activation, leading to elevated Racl activity and spine formation $[15,16]$. Moreover, Tiam1 forms a complex with Par3 (partitioning defective gene 3 ), a regulatory protein for cell polarization, and is restricted to the synapse. This regulation is important for the local activation of Racl and spine morphogenesis [17]. Interestingly, Tiam1 is also regulated by MAP1B (microtubule-associated protein $1 \mathrm{~B}$ ) and participates in NMDA-induced long-term depression (LTD) through Racl-dependent endocytosis of AMPA ( $\alpha$-amino-3-hydroxy-5-methyl-4-isoxazolepropionic acid) receptors and spine shrinkage [18]. These seemingly contradictory findings of Tiaml on both spine formation and elimination have been possibly explained by the following study. Tiaml interacts and cooperates with BCR (breakpoint cluster region), a Rac GAP at the synapse, and the two counteract each other on Racl activity and spine morphogenesis [19]. This Rac GEF-GAP complex possibly secures a dynamic and balancing module for regulating spine structure, receptor internalization, and synaptic plasticity, whereas disrupting either component may cause abnormal activation of the other.

Besides regulating synaptic function, Tiaml plays multifaceted roles in developmental stages of the nervous system. Tiaml is highly expressed in the intermediate zone and the cortical plate of developing cortex. The Rac GEF activity of Tiaml is required for the radial migration of newborn cortical neurons, and both Racl-regulated leading process formation and JNK-regulated microtubule organization are implicated in Tiaml-regulated neuronal migration [20]. Moreover, Tiaml acts as a converging transducer of a number of signals, including neurotrophins (such as nerve growth factor (NGF) and brain-derived neurotrophic factor (BDNF)), ephrins, and Wnts, to regulate neurite outgrowth and neural differentiation [21-24]. Tiaml is also involved in the development of the myelinating glial cells oligodendrocytes and Schwann cells, suggesting a role of Tiaml for the myelination of neurons in both central and peripheral nervous system $[25,26]$. Moreover, the gene expression of Tiam1 is downregulated in specific neuronal types in response to cocaine and oxygen/glucose deprivation, which is one of possible molecular changes that cause synaptic structural or functional alterations in these pathological conditions [27, 28].

Tiam2, also known as STEF (Sif- and Tiam1-like exchange factor), is the second member of Tiam protein family. Tiam2 is far less studied than Tiaml, and its neuronal function revealed thus far is the regulation of neurite outgrowth [29, 30]. In particular, protein kinase A (PKA) dependent phosphorylation of Tiam 2 activates the Rac GEF activity of Tiam2, which is a critical signaling pathway underlying dibutyryl cAMP (dbcAMP) induced neurite extension of neuroblastoma cells [30].

2.2. Trio and Kalirin. Trio and Kalirin (also known as Duo), both having several isoforms, are multidomain containing Rac GEFs that share high sequence homology. Trio is ubiquitously expressed and plays critical roles in early development of the nervous system, whereas Kalirin is specifically enriched in brain and elicits essential regulatory effects on synapse morphogenesis and function.

Mice with complete deletion of Trio display embryonic lethality with malformed myofibers and defective organizations in several brain regions including hippocampus and olfactory bulb [31]. Further characterization of these Trio knockout mice revealed that Trio transduces signaling from the chemoattractant netrin-1 through binding to the netrin1 receptor DCC (deleted in colorectal cancer), thus guiding the outgrowth and projection of commissure axons of cortical neurons [32]. Trio is tyrosine phosphorylated by Fyn, a member of Src family kinases, in response to netrin-1 stimulation, which is essential for DCC localization and netrin-induced Racl activation and axon growth [33]. Moreover, Trio is implicated in NGF-mediated neurite outgrowth via binding to the membrane protein Kidins220/ARMS [34]. Several neuronal isoforms of Trio have been identified and they also exhibit activities on neurite outgrowth $[35,36]$. To understand the neuronal roles of Trio, mice with specific deletion of Trio in the developing nervous system have been generated. These mice show remarkably reduced brain size and body weight, severe ataxia, and neonatal death. Disrupted cerebellum development including aberrant granule cell migration and abnormal neurite growth is observed in these mice, suggesting a critical role of Trio in cerebellum development [37]. 
TABLE 1: Summary of Rac GEFs and GAPs in the nervous system.

\begin{tabular}{|c|c|c|c|c|}
\hline Name (aliases) & Functions in the nervous system & Upstream signals & Neurological disease relevance & $\begin{array}{c}\text { Other targeted } \\
\text { GTPases }\end{array}$ \\
\hline \multicolumn{5}{|c|}{ Dbl-like Rac GEFs } \\
\hline Tiaml & $\begin{array}{l}\text { Spine morphogenesis; neuronal } \\
\text { migration; neurite outgrowth; } \\
\text { neural differentiation; glial cell } \\
\text { myelination }\end{array}$ & $\begin{array}{c}\text { BDNF/TrkB; NGF/TrkA; } \\
\text { NT3/TrkC; ephrinB1/EphB2; } \\
\text { Wnts; CaMKII }\end{array}$ & & $\mathrm{Cdc} 42$ \\
\hline Tiam2 (STEF) & Neurite outgrowth & dbcAMP & & Cdc42 \\
\hline Trio & $\begin{array}{l}\text { Axon guidance; neurite } \\
\text { outgrowth; cerebellum } \\
\text { development; neuronal cluster } \\
\text { organization in hindbrain }\end{array}$ & Netrin/DCC; NGF; Notch & & RhoA \\
\hline Kalirin-7 & $\begin{array}{l}\text { Spine morphogenesis; synaptic } \\
\text { plasticity; learning and memory; } \\
\text { dendritic growth of } \\
\text { interneurons; regulation of iNOS }\end{array}$ & $\begin{array}{c}\text { EphB2; CaMKII; N-cadherin; } \\
\text { 5- } \mathrm{HT}_{2 \mathrm{~A}} \text { serotonin receptors; } \\
\text { neuregulin/ErbB4 }\end{array}$ & $\begin{array}{l}\text { Alzheimer's disease; ischemic } \\
\text { stroke; schizophrenia; cocaine } \\
\text { addiction; attention deficit } \\
\text { hyperactivity disorder; } \\
\text { Huntington's disease }\end{array}$ & \\
\hline Kalirin-9 & $\begin{array}{l}\text { Dendritic outgrowth and } \\
\text { branching; spine morphogenesis }\end{array}$ & & Schizophrenia & RhoA \\
\hline Kalirin-12 & $\begin{array}{l}\text { Dendritic outgrowth and } \\
\text { branching; endocytosis }\end{array}$ & & & RhoA \\
\hline $\begin{array}{l}\alpha \text {-PIX } \\
(\text { ARHGEF6/Cool-2) }\end{array}$ & $\begin{array}{l}\text { Spine morphogenesis; axon and } \\
\text { dendrite branching; learning and } \\
\text { memory }\end{array}$ & Reelin & X-linked mental retardation & Cdc42 \\
\hline $\begin{array}{l}\beta \text {-Pix } \\
(\text { ARHGEF7/Cool-1) }\end{array}$ & $\begin{array}{l}\text { Spine formation; presynaptic } \\
\text { vesicle positioning; } \mathrm{GABA}_{\mathrm{A}} \\
\text { receptor stabilization; neurite } \\
\text { and dendrite outgrowth }\end{array}$ & CaMKII & & $\mathrm{Cdc} 42$ \\
\hline Farp1 (CDEP) & $\begin{array}{l}\text { Dendritic arborization; spine } \\
\text { morphogenesis; presynaptic } \\
\text { active zone modulation }\end{array}$ & $\begin{array}{c}\text { Sema3A/PlexinA1; } \\
\text { Sema6A/PlexinA4; retinoids; } \\
\text { SynCAM1 }\end{array}$ & & \\
\hline Farp2 (FIR/FRG) & Axon guidance; dendrite growth & Sema3A/PlexinA1, PlexinA4 & & Cdc42 \\
\hline P-Rexl & $\begin{array}{l}\text { Neurite outgrowth; neuronal } \\
\text { migration; cerebellum } \\
\text { development and function }\end{array}$ & NGF; BDNF; ephrin-B1 & & \\
\hline P-Rex2 & $\begin{array}{l}\text { Cerebellum development and } \\
\text { function }\end{array}$ & PI3K & & \\
\hline Vav2 & $\begin{array}{l}\text { Neurite outgrowth; axon } \\
\text { guidance; spine development }\end{array}$ & $\begin{array}{c}\text { Ephrin/Eph; BDNF/TrkB; } \\
\text { NGF/PI3K }\end{array}$ & & $\mathrm{Cdc} 42$ \\
\hline Vav3 & $\begin{array}{l}\text { Neurite outgrowth; axon } \\
\text { guidance; spine development; } \\
\text { cerebellum development; } \\
\text { GABAergic neuron transmission } \\
\text { in brainstem }\end{array}$ & $\begin{array}{c}\text { Ephrin/Eph; BDNF/TrkB; } \\
\text { NGF/PI3K }\end{array}$ & Schizophrenia & $\mathrm{Cdc} 42$ \\
\hline $\begin{array}{l}\text { Plekhg4 } \\
\text { (puratrophin-1) }\end{array}$ & Cerebellar function & & Spinocerebellar ataxia & RhoA; Cdc42 \\
\hline GEFT & Neurite and dendrite growth & Retinoic acid; dbcAMP & & Cdc42 \\
\hline RasGRF1 & $\begin{array}{l}\text { Neurite growth; synaptic } \\
\text { plasticity; learning and memory; } \\
\text { striatal function }\end{array}$ & & $\begin{array}{c}\text { Epilepsy; L-dopa-induced } \\
\text { dyskinesia }\end{array}$ & Ras \\
\hline RasGRF2 & $\begin{array}{l}\text { Neurite growth; synaptic } \\
\text { plasticity; alcohol-induced } \\
\text { reinforcement }\end{array}$ & & Alcoholism & Ras \\
\hline Alsin & $\begin{array}{l}\text { Motoneuron protection; } \\
\text { endosomal trafficking; neurite } \\
\text { outgrowth }\end{array}$ & & $\begin{array}{c}\text { Amyotrophic lateral sclerosis; } \\
\text { primary lateral sclerosis; } \\
\text { infantile-onset ascending } \\
\text { hereditary spastic paralysis }\end{array}$ & Rab5 \\
\hline
\end{tabular}


TABle 1: Continued.

\begin{tabular}{|c|c|c|c|c|}
\hline Name (aliases) & Functions in the nervous system & Upstream signals & Neurological disease relevance & $\begin{array}{l}\text { Other targeted } \\
\text { GTPases }\end{array}$ \\
\hline \multicolumn{5}{|c|}{ Atypical Rac GEFs } \\
\hline Dock1 (Dock180) & Spine morphogenesis & Netrin/DCC; RhoG & & \\
\hline Dock2 & $\begin{array}{l}\text { Microglia function and } \mathrm{A} \beta \\
\text { deposition }\end{array}$ & Prostaglandin E2 & Alzheimer's disease & \\
\hline Dock3 (MOCA/PBP) & $\begin{array}{l}\text { Axonal outgrowth; } \\
\text { neuroprotection }\end{array}$ & $\mathrm{BDNF} / \operatorname{TrkB}$ & $\begin{array}{c}\text { Alzheimer's disease; } \\
\text { glaucoma; attention deficit } \\
\text { hyperactivity disorder }\end{array}$ & \\
\hline Dock4 & $\begin{array}{l}\text { Neurite and dendrite } \\
\text { development; spine } \\
\text { morphogenesis }\end{array}$ & Retinoic acid & $\begin{array}{l}\text { Autism; dyslexia; } \\
\text { schizophrenia }\end{array}$ & \\
\hline Dock6 (Zirl) & Axonal growth and regeneration & & & $\mathrm{Cdc} 42$ \\
\hline Dock7 (Zir2) & $\begin{array}{l}\text { Neuronal polarity; cortical } \\
\text { neurogenesis; Schwann cell } \\
\text { differentiation and myelination; } \\
\text { axon terminal development of } \\
\text { chandelier cells }\end{array}$ & Neuregulin/ErbB2, ErbB4 & $\begin{array}{l}\text { Epileptic encephalopathy and } \\
\text { cortical blindness }\end{array}$ & $\mathrm{Cdc} 42$ \\
\hline \multicolumn{5}{|c|}{ Rac GAPs } \\
\hline BCR & $\begin{array}{l}\text { Dendrite growth; spine } \\
\text { morphogenesis; astroglia } \\
\text { development; learning and } \\
\text { memory }\end{array}$ & $\mathrm{BDNF} / \operatorname{TrkB}$ & & $\mathrm{Cdc} 42$ \\
\hline $\mathrm{ABR}$ & $\begin{array}{l}\text { Dendrite growth; spine } \\
\text { morphogenesis; astroglia } \\
\text { development; learning and } \\
\text { memory }\end{array}$ & & & $\mathrm{Cdc} 42$ \\
\hline $\begin{array}{l}\alpha 1 \text {-Chimaerin } \\
(\mathrm{n} \text {-chimaerin) }\end{array}$ & Dendrite and spine development & Diacylglycerol & Duane's retraction syndrome & \\
\hline$\alpha 2$-Chimaerin & $\begin{array}{l}\text { Axon guidance in oculomotor } \\
\text { and motor system; neuronal } \\
\text { migration; cognitive function }\end{array}$ & $\begin{array}{l}\text { Ephrin/Eph; Sema3/PlexinA; } \\
\text { BDNF/TrkB; CXCL12; HGF }\end{array}$ & Duane's retraction syndrome & \\
\hline$\beta 2$-Chimaerin & Axonal pruning & Sema3F & & \\
\hline srGAP2 (FNBP2) & $\begin{array}{l}\text { Neuronal migration; spine } \\
\text { development; neurite outgrowth }\end{array}$ & Slit/Robo; valproic acid & Schizophrenia; epilepsy & $\mathrm{Cdc} 42$ \\
\hline $\begin{array}{l}\text { srGAP3 } \\
\text { (MEGAP/WRP) }\end{array}$ & $\begin{array}{l}\text { Spine development; synaptic } \\
\text { plasticity; learning and memory; } \\
\text { neural progenitor cell } \\
\text { differentiation and migration; } \\
\text { neurite outgrowth }\end{array}$ & Slit/Robo; valproic acid & $\begin{array}{l}\text { Hydrocephalus; X-specific } \\
\text { mental retardation; } \\
\text { schizophrenia; epilepsy }\end{array}$ & \\
\hline ArhGAP4 & Axon growth & & & \\
\hline $\begin{array}{l}\text { p250GAP } \\
\text { (Grit/RICS/p250GAP/ } \\
\text { p200RhoGAP/GC- } \\
\text { GAP) }\end{array}$ & $\begin{array}{l}\text { Dendritic and spine } \\
\text { morphogenesis; axon guidance } \\
\text { and branching; neurite } \\
\text { outgrowth; neuronal migration }\end{array}$ & BDNF; NGF/TrkA; leptin & Schizophrenia & RhoA; Cdc42 \\
\hline PX-RICS & Neurite outgrowth & & & \\
\hline Richl (Nadrin) & $\begin{array}{l}\text { Spine morphogenesis; neurite } \\
\text { outgrowth; astrocyte } \\
\text { differentiation }\end{array}$ & NGF & & RhoA; Cdc42 \\
\hline Rich2 & $\begin{array}{l}\text { Spine morphogenesis and } \\
\text { synaptic plasticity }\end{array}$ & & & \\
\hline SH3BP1 (3BP-1) & Growth cone collapse & Sema3E/PlexinD1 & & \\
\hline BARGIN & ROS diminishing & & Alzheimer's disease & \\
\hline $\begin{array}{l}\text { CrossGAP } \\
\text { (CrGAP/Vilse) }\end{array}$ & $\begin{array}{l}\text { Axon guidance and spine } \\
\text { morphogenesis }\end{array}$ & Slit/Robo & & $\mathrm{Cdc} 42$ \\
\hline $\begin{array}{l}\text { MgcRacGAP } \\
(\text { RacGAP1/Cyk4) }\end{array}$ & Neuronal migration & & & \\
\hline
\end{tabular}


Alternative splicing of the KALIRIN gene (KALRN) generates several transcripts encoding functionally distinct proteins, among which Kalirin-7 is the most prevalent isoform in mature neurons. Kalirin-7 is one of the critical integrators localized at the postsynaptic density of excitatory synapses to promote activity-dependent dendritic spine morphogenesis. Kalirin-7 is regulated at the synaptic areas through several mechanisms. First, Kalirin-7 is targeted to the synaptic membrane by interacting with synaptic proteins, such as PSD95/PDZ-containing proteins and the $\mathrm{N}$-cadherin adhesion molecule complex, leading to local activation of Racl and spine formation [38, 39]. Second, Kalirin-7 is extensively phosphorylated at the postsynaptic density, indicating that it is a converging signaling target and dynamically regulated by multiple kinases at the synapses [40]. In particular, the Rac GEF activity of Kalirin-7 is activated by synaptic EphB2 receptors and CaMKII via tyrosine and threonine phosphorylation, respectively [41, 42]. Moreover, Kalirin-7 is regulated by $5-\mathrm{HT}_{2 \mathrm{~A}}$ serotonin receptors and participates in serotonin-modulated spine size increase of cortical pyramidal neurons [43]. Besides regulating spine structure, Kalirin-7 also binds to the neurotransmitter NMDA and AMPA receptors and regulates their expressions and functions $[42,44]$. To understand the in vivo roles of Kalirin-7 and other Kalirins in synapse structure and function, mice with only Kalirin7 isoform deleted and mice with the KALRN gene deleted (in which all the Kalirin isoforms are absent) were generated. Interestingly, different phenotypical abnormalities were observed in these two lines of mice. For instance, spine morphogenesis and glutamatergic neurotransmission in cortex, but not hippocampus, are significantly reduced in KALRN knockout mice, and these mice exhibit age-dependent behavioral deficits such as reduced working memory, sociability, prepulse inhibition, and hyperactivated locomotion [45]. By contrast, only modest alterations are observed in the hippocampus, possibly associated with impaired fear conditioning in these mice [46]. On the other hand, Kalirin-7 knockout mice showed decreased spine density in hippocampus and abnormal anxiety-like behavior, but locomotion and spatial working memory are normal in these mice [47]. Since the expression of larger Kalirin isoforms, Kalirin-8, -9, and -12 , is upregulated in Kalirin-7 knockout cortex [47], the discrepancies in these two lines of mice suggest nonoverlapping functions of Kalirin-7 and other Kalirins. The larger Kalirin isoforms have an additional RhoA GEF domain, which may thus contribute to their unique functions [48]. Indeed, Kalirin-9 and Kalirin-12 specifically regulate dendritic outgrowth and branching of cortical neurons, whereas overexpression of Kalirin-9 surprisingly decreases spine size and density $[49,50]$. Kalirin-12 is also implicated in dynamindependent endocytosis in neuronal cells [51].

Being a critical synaptic regulator, KALRN has been found as a high risk gene of a variety of neurological diseases [52]. Both gene and protein expressions of Kalirin were decreased in the hippocampus of Alzheimer's disease (AD) patients in a study, and the lowered Kalirin level may contribute to higher iNOS (inducible nitric oxide synthase) activity observed in the hippocampal specimens of the patients [53, 54]. Moreover, KALRN expression is decreased in schizophrenia patients, and Kalirin-7 interacts with several schizophrenia-related proteins. The localization of Kalirin-7 and the duration of Racl activation are regulated by the schizophrenia-related factor DISC1 (disrupted-inschizophrenia 1) [55]. Moreover, Kalirin-7 is a downstream mediator of the schizophrenia-related neuregulin/ErbB4 signaling, regulating dendritic spine morphogenesis of cortical pyramidal neurons and dendritic growth of cortical interneurons [56, 57]. Importantly, a sequence variant of KALRN found in schizophrenia patients encodes a Kalirin-7 mutant with diminished Rac GEF activity, and this mutant fails to increase spine density and size [58]. Expression of Kalirin-9, on the other hand, was found to be upregulated in schizophrenia subjects [49]. Moreover, Kalirin has been shown as a converging modulator in various pathological conditions such as those induced by cocaine and ischemia [59-61].

2.3. PIX. The PIX (p21-activated kinase (PAK) interacting exchange factor) protein family includes $\alpha$ PIX (ARHGEF6) and $\beta$ PIX (ARHGEF7). $\alpha$ PIX/ARHGEF6 gene is one of the causative genes of X-linked intellectual disability (ID) [62]. $\alpha \mathrm{PIX}$ is expressed primarily in the hippocampus and is localized to the postsynaptic density of excitatory neurons [63, 64]. $\alpha$ PIX regulates spine morphogenesis through interacting with the postsynaptic adaptor protein GIT1 (G-protein coupled receptor kinase-interacting protein 1 ) and activation of Rac and PAK3 $[63,65]$. In the early development of neurons, $\alpha$ PIX promotes axon and dendrite branching and participates in dendritic Golgi translocation in response to reelin $[66,67]$. $\alpha$ PIX knockout mice exhibit disrupted synaptic plasticity and a series of behavioral abnormalities, including impaired spatial and complex learning and less behavioral control in mildly stressful situations, resembling typical ID symptoms [64].

$\beta$ PIX plays roles at both excitatory and inhibitory synapses. At excitatory synapse, $\beta$ PIX forms a complex with important postsynaptic molecules including Shank and GIT1 and regulates synaptogenesis [68]. $\beta$ PIX is phosphorylated by CaMKII in response to neuronal activity induced $\mathrm{Ca}^{2+}$ influx, which causes activation of $\beta$ PIX toward Racl and spine formation [69]. $\beta$ PIX also forms a complex with cadherin, $\beta$-catenin, and scribble at presynaptic sites and regulates synaptic vesicle positioning [70]. Interestingly, the GIT1 and $\beta$ PIX complex is also localized to inhibitory synapses and regulates the synaptic stability of $\mathrm{GABA}_{\mathrm{A}}$ receptors [71]. The ability of $\beta$ PIX in regulating both excitatory and inhibitory synapses suggests that it may be an essential modulator of synaptic balance. Moreover, $\beta$ PIX is involved in several signaling pathways that regulate neurite and dendritic outgrowth [72-74]. This is controversial to a recent report that $\beta$ PIX knockdown has no effect on dendritic growth and branching [66]. These observations may be due to the presence of different isoforms of $\beta$ PIX that may play additional functions during neuronal development $[66,75]$.

2.4. Farp. Farp (4.1, ezrin, radixin and moesin (FERM), RhoGEF (ARHGEF), and pleckstrin domain protein) family 
includes two closely related members, Farp1 and Farp2. Both Farps function as mediators of Semaphorin (Sema)/Plexin signaling. Farpl interacts with PlexinA1 receptors and is required for Sema3A-promoted dendritic arborization of hippocampal neurons, which is a neuronal activity-dependent process [76]. Moreover, Farp1 is a responsive gene of retinoids in the developing spinal cord, where it mediates Sema6A/PlexinA4 signaling induced dendritic growth of spinal motoneurons [77]. On the other hand, although Farp2 also binds to PlexinAl receptors, this interaction is diminished by Sema3A during axonal repulsion of dorsal root ganglion (DRG) neurons [78]. Dissociation of Farp2 from PlexinA1 increases Farp2's GEF activity toward Racl and subsequently activates other signaling events, leading to repulsion and decreased adhesion of axons [78]. A recent study dissected the functional roles of different cytoplasmic domains of PlexinA4 and compared the requirement of Farp1 and Farp2 in Sema3A/PlexinA4 signaling. It reveals that Farp1 and Farp2 bind to PlexinA4 in different fashions, and only Farp2 is required for Sema3A/PlexinA4 induced growth cone collapse of DRG neurons and dendritic growth of cortical neurons [79]. Besides acting as an effector of Sema/Plexin signals, it is found that Farp1 interacts with SynCAM1 (synaptic cell adhesion molecule 1), a synaptogenic protein, and regulates synapse formation. Farpl works together with SynCAM1 to promote spine morphogenesis through activation of Racl and increase of F-actin polymerization in spine heads. Farp1 and SynCAM1 also activate a retrograde signaling on the modulation of presynaptic active zones [80].

2.5. P-Rex. P-Rex (phosphatidylinositol (3,4,5)-trisphosphate-dependent Rac exchanger) family, including P-Rexl and P-Rex2, is activated by both PI3K (phosphoinositide 3-kinase) and GPCRs (G-protein coupled receptors). P-Rex1 is localized to the distal tips of neurites and axonal growth cones and regulates NGF-stimulated neurite outgrowth through activating Racl and Rac3 [81]. Moreover, P-Rexl is expressed in the developing cortex and regulates both radial migration and tangential migration of newborn pyramidal neurons under the control of neurotrophins (such as NGF and BDNF) and ephrin-B1, respectively [82, 83].

Expression of P-Rex 2 in the brain is much more limited and is most prominently expressed in cerebellar Purkinje cells. Aberrant dendrite morphology of Purkinje cells was observed in P-Rex2 knockout mice, associated with motor coordination deficits. P-Rex1 and P-Rex2 double knockout mice exhibit more severe motor coordination defects together with ataxia, abnormal posture, and gait [84]. This suggests that P-Rex1 and P-Rex2 cooperatively regulate cerebellum function. Further studies using P-Rexl/2 double knockout mice show that PI3K-P-Rex signaling is important for late phase long-term potentiation (LTP) at the parallel fiberPurkinje cell synapse in cerebellum [85].

2.6. Vav. Three mammalian Vavs, Vav1, Vav2, and Vav3, have been identified in Vav protein family. Vavl is preferentially expressed in immune system, whereas Vav2 and Vav3 are more ubiquitous with higher expression in developing brain.
A number of studies have revealed that Vav2 and Vav3, in particular Vav2, participate in diverse signaling pathways to regulate neurite outgrowth and branching in vitro and in Xenopus spinal neurons [86-88]. Investigation of Vav2 and Vav3 single or double knockout mice has provided more information about the functional roles of these proteins in the nervous system. In early developmental stages, Vav2 and Vav3 are found to mediate ephrin/Eph signaling regulated axon guidance of ipsilateral retinogeniculate projections [89]. Vav2 binds to activated EphA4 receptors and its Rac GEF activity was stimulated by ephrin-A1. Such regulation induces endocytosis of the ephrin/Eph complex and a subsequent growth cone collapse of cultured retinal ganglion cells (RGCs). Importantly, deletion of both Vav2 and Vav3 in mice results in abnormal axon projection of RGCs to the dorsal lateral geniculate nucleus. In later developmental stages, Vav2 and Vav3 interact with $\operatorname{TrkB}$ receptors and are transiently activated upon TrkB stimulation by BDNF, leading to the activation of Rac1 [90]. Vav2 and Vav3 are dispensable for basal dendritic spine formation but are required for BDNF-induced rapid spine enlargement and theta-burst-stimulated LTP in hippocampus [90]. Other abnormalities identified in Vav2/Vav3 double knockout mice include delayed degeneration, revascularization and regeneration of peripheral nerves, and optic neuropathy associated with ocular deficits that are highly resemblance of glaucoma-like phenotypes [91, 92].

To address whether individual Vav plays nonoverlapping biological roles, single knockout mice of each Vav have been generated. In particular, two additional functions of Vav3 in the nervous system have been found. First, Vav3, but not Vav2, contributes to the development of cerebellum [93]. Vav3 regulates the precise timing of several developmental processes at postnatal stages, including dendritogenesis of Purkinje cell and the survival and migration of the granule cells. In line with the morphological defects of cerebellum, Vav3 knockout mice exhibit abnormalities in cerebellumrelated behaviors such as motor coordination and gaiting patterns [93]. Second, Vav3 specifically regulates the axon guidance of a subset of GABAergic neurons in the ventrolateral medulla (VLM), a brainstem area. This regulation controls the precise GABAergic transmission in VLM, which is eventually important for the modulation of blood pressure and respiratory rates [94]. Moreover, it was recently found that $V A V 3$ is a candidate gene for schizophrenia, pointing to the importance of investigating Vav3 in the molecular pathophysiology of schizophrenia [95].

2.7. Plekhg4. Plekhg4, a GEF enriched in adult cerebellum, has been identified to be linked with autosomal dominant spinocerebellar ataxia, a heritable neurodegenerative disease [96]. When expressed heterologously in fibroblast cells, Plekhg4 possesses general GEF activities toward RhoA, Racl, and Cdc42 and is capable of inducing actin-dependent formation of lamellipodia and filopodia [97]. The stability and subcellular localization of Plekhg 4 can be regulated by the chaperon complex of heat shock proteins [97]. Nonetheless, the function of Plekhg4 in the nervous system, especially the cerebellum, and how its dysfunction leads to cerebellar impairments still await further characterization. 
2.8. GEFT. GEFT, a small GEF that contains primarily a $\mathrm{DH}$ and a $\mathrm{PH}$ domain, is widely expressed in various brain regions. Overexpressed GEFT promotes dendrite and spine growth in hippocampal neurons and facilitates retinoic acid and dbcAMP induced neurite outgrowth in neuroblastoma cells $[98,99]$. Although GEFT may activate both Racl and Cdc42, its effect on neurite growth is possibly via Rac1/PAK pathway [98].

2.9. RasGRF. RasGRF protein family, including RasGRF1 and RasGRF2, has dual GEF activities toward both Ras and Rac and is expressed predominantly in mature neurons. RasGRFs play multiple roles in neurite outgrowth, synaptic plasticity, and neuronal behaviors $[100,101]$. In particular, RasGRF1 exhibits differential roles in regulating LTD, LTP, and dentate gyrus neurogenesis in an age-dependent manner $[102,103]$. RasGRF1 directly couples to NMDA receptor 2B subunits (NR2B) to participate in the induction of LTD and dendrite complexity development $[102,104,105]$. On the other hand, association of RasGRF2 with NMDA receptor 2A subunits (NR2A) is required for LTP generation $[102,106]$. As critical mediators of synaptic function, both RasGRFs are found to be essentially involved in physiological and pathological neural behaviors. For instance, RasGRF1 regulates learning and memory and is implicated in epilepsy, striatum-dependent motor behavioral deficits induced by cocaine, L-dopa, or amphetamine [107-112]. RasGRF2 is important for contextual discrimination and is found to be a responsible molecule for alcohol-induced reinforcement [113, 114].

Given that RasGRFs activate both Ras and Racl, detailed analysis has been performed to provide further information about whether both small GTPases or only one of them is important for specific RasGRF's function. In particular, Racl signaling is differentially activated in RasGRF1-mediated LTD [102]. Similarly, although the Ras GEF activity of RasGRF2 regulates synaptic strength and NMDA current, only its Rac GEF activity is activated immediately following stimulation of NMDA, which is in turn required for the rapid spine enlargement and LTP generation [115]. Importantly, the Rac GEF activity of RasGRFs may be differentially regulated by protein interaction and phosphorylation. For instance, the Rac GEF activity of RasGRF1 is specifically inhibited by the microtubule-destabilizing factor SCLIP (SCG10-like protein), which antagonizes the neurite outgrowth induced by RasGRF1 [116]. Moreover, the Rac GEF activity of RasGRF2 is decreased by p35/Cdk5 via phosphorylation [117].

2.10. Alsin. The gene encoding Alsin, ALS2, is a causative gene of several motoneuron degenerative diseases, including juvenile amyotrophic lateral sclerosis (ALS), primary lateral sclerosis, and infantile-onset ascending hereditary spastic paralysis [118]. Alsin has dual GEF activities for both Rab5, a member of Rab GTPases essential for protein trafficking through early stages of the endocytic pathway, and Racl. A battery of studies in cells and in ALS2 knockout mice have revealed a broad range of cellular functions of Alsin, including protection of motoneuron survival, endosomal trafficking of neuronal membrane proteins, and neurite outgrowth [119-124]. Both Rab5 and Racl contribute to these functions mediated by Alsin. In particular, knockdown of Alsin in cultured rat spinal motoneurons leads to reduced endosome size, abnormal protein trafficking, and elevated neuronal death [121]. Activation of Racl, but not Rab5, rescues these defects in Alsin deficient neurons [121]. Thus, although Rab5 may contribute to Alsin-regulated endosomal trafficking, Rab5 is not essentially required in Alsin-regulated neuronal functions. In agreement with this finding, the membrane and endosomal localization of Alsin is reciprocally regulated by activated Racl, suggesting that activation of Rac1 may be a signaling event prior to that of $\operatorname{Rab5}[125,126]$. Moreover, the Rac GEF activity, in particular Rac1/PI3K/Akt3 pathway, is involved in Alsin-regulated protective effects against motoneuron death induced by mutant forms of SOD1 (superoxide dismutase 1), another causative gene in ALS $[120,127]$. Rac1/PAK pathway is also important for Alsinregulated neurite outgrowth [119]. However, Alsin knockout mice exhibit no obvious motoneuron death and only mild motor defects [118]. The poor recapitulation to phenotypes in human diseases may be due to compensatory effects from other ALS-related genes such as SOD1. Indeed, loss of ALS2 in a ALS-related SOD1 mutant mice exacerbates neurotoxicity, accumulation of misfolded proteins, and motor dysfunction of the mutant mice [128].

\section{Dock Family Atypical Rac GEFs}

Dock (dedicator of cytokinesis) protein family is a family of atypical GEFs which contains 11 members, of which Dock15 activate Rac1 and Dock6 and Dock7 activate both Rac1 and Cdc42 [129]. Except Dock5, the other six members of these Rac GEF activity-possessing Docks all have known functions in the nervous system. Dock1, also called Dock180, is involved in the regulation of axon guidance and dendritic spine morphogenesis. Dock180 binds to the netrin receptor DCC and mediates netrin-induced Racl activation and axon growth [130]. Interestingly, Dock180 is also important for the axon pruning induced by ephrin-B3 reverse signaling and RhoG, suggesting a bifaced role of Dock180 in axon attraction and repulsion [131, 132]. Moreover, Dock180 promotes Rac1 activation and leads to dendritic spine morphogenesis in hippocampal neurons [133].

Dock2 is expressed exclusively in microglia and is implicated in neuroinflammation of AD pathology. It has been shown that the number of Dock2-expressing microglia is abnormally increased in brains of AD patients and the expression of Dock2 is positively regulated by prostaglandin E2 receptors [134]. Additionally, Dock2 deficiency significantly reduces the area and size of $\beta$-amyloid $(\mathrm{A} \beta)$ plaque in cerebral cortex and hippocampus of a mouse model of AD [135].

Dock3 plays major roles in neurite outgrowth and neuroprotection and is implicated in several neurological diseases such as AD and glaucoma [136]. Dock3 mediates several molecular events that are important for BDNF-induced neurite and axon growth $[137,138]$. More importantly, Dock3 exerts several neuroprotective effects, whereas loss of Dock3 leads to axon degeneration [139]. Dock3 decreases the secretion of APP (amyloid precursor protein) and A $\beta$ peptide 
by accelerating the proteasome-dependent degradation of APP [140]. Moreover, Dock3 ameliorates the neurotoxicity induced by NMDA receptors via interacting with the Cterminus of NMDA receptor subunits $[141,142]$. These findings suggest that Dock3 is a potential therapeutic target for nerve injury and degeneration. Indeed, two recent findings have shown that Dock3 stimulates neuroprotection after optic nerve injury and protects myelin in a demyelination model of multiple sclerosis $[143,144]$.

The gene encoding Dock 4 has been found to be associated with several neuropsychiatric diseases, including autism, dyslexia, and schizophrenia [145-147]. Dock4 regulates neurite and dendrite outgrowth through Racl-dependent actin cytoskeleton reorganization [148]. Dock4 is also important for spine morphogenesis of hippocampal neurons [149].

Dock6 has been found to promote neurite outgrowth and regulate axonal growth and regeneration of sensory neurons $[150,151]$. Although Dock6 is capable of activating both Rac1 and Cdc42 in vitro, it preferentially activates Racl in DRG neurons [151]. The GEF activity of Dock6 towards Racl is regulated by phosphorylation/dephosphorylation at Ser1194 by Akt kinase and protein phosphatase PP2A.

Dock7 is highly expressed in the developing brain and has been found to play important roles in several neuronal developmental processes. Dock7 regulates the neurogenesis in the neocortex by promoting the differentiation of radial glial progenitor cells into basal progenitors and neurons [152]. Dock7 also plays a role in controlling neuronal polarity and axon formation [153]. A recent study has revealed that Dock7 is expressed in chandelier cells, an important type of interneurons for modulating cortical circuits, and regulates axonal terminal development of these cells under the control of ErbB4 receptors [154]. Notably, mutations in DOCK7 were found in individuals with epileptic encephalopathy and cortical blindness [155]. In the peripheral nervous system, Dock7 is important for the development of Schwann cells, the glial cells that ensheath the axons of motor and sensory neurons. Dock7 negatively regulates the differentiation of Schwann cells and the onset of myelination in both primary Schwann cells in vitro and sciatic nerves in vivo [156]. Moreover, Dock7 promotes Schwann cell migration mediated by neuregulin-ErbB2 receptors [157].

\section{Rac GAPs}

4.1. $B C R$ and $A B R$. BCR and ABR (active BCR-related) are two closely related Rac GAPs expressed mainly in the brain. $\mathrm{ABR}$ and $\mathrm{BCR}$ have both GAP and GEF domains but only exhibit GAP activity in vivo. Knockout of both ABR and BCR or either of them in mice leads to elevated Racl activity in the brain $[158,159]$. Defects observed in the knockout mice include functional and structural abnormalities of astroglia in postnatal cerebellar development, increased dendritic arborization and spine number, and defective LTP maintenance in the hippocampus [158-160]. Moreover, BCR coexists with Tiaml as a Rac GEF-GAP complex to regulate spine morphogenesis and synaptic plasticity under the control of BDNF-TrkB signals [19]. Either ABR or BCR knockout mice exhibit impaired spatial and object recognition memory
[158]. The GAP activity of BCR can be promoted by phosphorylation at its $\mathrm{Tyr}^{177}$ residue [160]. Fyn and protein tyrosine phosphatase receptor $\mathrm{T}$ (PTPRT) are the upstream kinase and phosphatase, respectively, that regulate BCR activity via targeting the $\mathrm{Tyr}^{177}$ residue [160].

4.2. Chimaerin. Chimaerins are a family of Rac GAPs which contain a GAP domain homologous to that of BCR. Two subfamilies of chimaerins, $\alpha$-chimaerins encoded by $C H N 1$ gene and $\beta$-chimaerins encoded by $\mathrm{CHN} 2$ gene, are identified in mammals. There are three alternative spliced products of each of $C H N 1$ and $C H N 2$ : $\alpha 1$ - and $\beta 1$-chimaerins contain a $\mathrm{C} 1$ domain and a GAP domain, $\alpha 2$ - and $\beta 2$-chimaerin possess an additional SH2 domain at the $\mathrm{N}$-terminus, and $\alpha 3$ - and $\beta 3$-chimaerin only contain a GAP domain [161].

Among the different members of chimaerins, $\alpha 2$ chimaerins are the most studied and have been revealed to play crucial functions in the nervous system. Mutation of the CHN1 gene is one of the causes of Duane's retraction syndrome (DRS), a complex congenital eye movement disorder caused by aberrant axonal innervation of the extraocular muscle [162]. A number of heterozygous missense mutations in CHN1 have been found in DRS and all cause hyperactivation, that is, gain of function, of the GAP activity of chimaerin and misguidance of oculomotor nerves [162]. Further molecular dissection has shown that $\alpha 2$-chimaerin acts as a downstream mediator of both the repellent signals of oculomotor axon guidance, that is, Sema3/PlexinA, and the attractant signals, that is, the chemokine CXCL12 and hepatocyte growth factor (HGF) [163]. The ability of $\alpha 2$ chimaerin to respond to both positive and negative signals suggests that $\alpha 2$-chimaerin represents a balancing intermediate which maintains the high sensibility of axons to the surrounding microenvironment.

Besides regulating axon guidance in oculomotor system, $\alpha 2$-chimaerin is also critical in the axon pathfinding of corticospinal tract and spinal cord neurons during motor circuit assembly. $\alpha 2$-Chimaerin functions as an indispensable effector of ephrin/Eph repellent signaling pathway to restrict the axons to project into the ipsilateral side of the spinal cord without crossing the midline [164-167]. Such function of $\alpha 2$-chimaerin controls alternate body movement, whereas knockout of $\alpha 2$-chimaerin results in locomotion defects and involuntary synchronous arrhythmic stepping, known as a rabbit-like hopping gait $[164,166-168]$. The molecular regulation of $\alpha 2$-chimaerin activation includes membrane recruitment and tyrosine phosphorylation of $\alpha 2$-chimaerin by Eph receptors and binding to the adaptor protein Nck family, which leads to Racl in activation and growth cone collapse $[164,165,169]$.

Interestingly, despite the hopping gait behavior, $\alpha 2$ chimaerin null mice exhibit enhanced contextual fear learning. Such behavior abnormalities are only observed when $\alpha 2$-chimaerin is genetically deleted in early developmental stages, but not in adulthood [170]. One of the roles of $\alpha 2-$ chimaerin in early development is the regulation of the radial migration and positioning of newborn pyramidal neurons during corticogenesis. Such regulation is a key determinant 
of normal cortical excitability and seizure threshold in adulthood [171]. On the other hand, $\alpha 1$-chimaerin, the shorter splicing variant of $\alpha 2$-chimaerin, is enriched in later developmental stages and is not involved in gait behavior or contextual fear learning [170]. $\alpha 1$-Chimaerin plays a role in pruning of dendritic branches and spines, and such effect may be regulated by synaptic activity and interaction with NMDA receptors $[172,173]$.

The function of $\beta$-chimaerins in the nervous system is less understood comparing to $\alpha$-chimaerins. One report has revealed that $\beta 2$-chimaerin acts as a mediator of Sema3F signaling in regulating axonal pruning in developing hippocampus [174].

4.3. $s r G A P$. The Slit-Robo GAP (srGAP) family is an FBAR (Bin, Amphiphysin, and Rvs) domain containing GAP family that has four members, srGAP1, srGAP2, srGAP3, and ArhGAP4. Among these members, srGAP1 preferentially inhibits Cdc42, whereas srGAP2 and srGAP3 downregulate Racl. ArhGAP4 may be implicated in the inhibition of axon growth, but its function has been largely unknown [175].

srGAP2 negatively regulates radial migration of cortical neurons through its F-BAR domain mediated increase of leading process branching [176]. The GAP activity of srGAP2 toward Racl partially contributes to srGAP2-induced neurite branching and migration inhibition [176]. Moreover, srGAP2 promotes maturation of dendritic spines but decreases sine density in the neocortex [177]. Notably, it is found that $S R G A P 2$ is one of the human-specific duplicated genes, which undergoes incomplete duplications that generate several partial SRGAP2 products in the human brain $[177,178]$. srGAP2C, encoded by one of the major duplications, forms dimers with srGAP2 and inhibits srGAP2 function on migrating inhibition and spine maturation, suggesting that srGAP2 is modulated by its paralogs in human brain [177].

srGAP3, also called MEGAP (mental disorder associated GAP protein) or WRP (WAVE (Wiskott-Aldrich syndrome protein verprolin-homologous) associated Rac GTPase-activating protein), is a factor linked to mental retardation [179]. srGAP3 controls the early stages of dendritic spine formation in an F-BAR domain dependent manner and is dispensable for the maintenance of spine density [180]. The in vivo functions of srGAP3 on synapse structure and function have been revealed in several lines of srGAP3 knockout mice. Mice with deletion of srGAP3 in brain show deficits in multiple long-term learning and memory tasks, including novel object recognition, water maze, and passive avoidance [180]. In another study, a line of complete srGAP3 knockout mice show schizophrenia-like behaviors, such as impaired social behavior, working memory and prepulse inhibition, more spontaneous tics, and exacerbated methylphenidate-induced locomotor hyperactivation [181]. However, the long-term memory is surprisingly normal in these complete srGAP3 knockout mice. Moreover, srGAP3 interacts with the actin regulatory scaffold WAVE-1 and regulates synapse morphogenesis and function. Mice with disrupted WAVE-1-srGAP3 interaction show decreased spine density, elevated LTP, and impaired retention of spatial memory [182]. Notably, srGAP3 knockout mice exhibit perinatal-onset hydrocephalus, which is possibly due to cerebral aqueductal occlusion caused by abnormal migration and differentiation of progenitor cells from the ventricular region into the corpus callosum $[181,183]$. Studies in neuroblastoma cells and cultured embryonic neural progenitor cells have confirmed that srGAP3 negatively regulates neuronal differentiation and neurite outgrowth $[184,185]$. Such effect of srGAP3 may involve interaction with Brg1 (Brahma-related gene 1), a modulator of chromatin remodeling enzymes, and an interplay of other srGAPs such as srGAP2 [186, 187]. Other functions of srGAP3 include the positioning of commissural axons of spinal cord neurons, possibly under the regulation of Slit-Robo signals [188].

4.4. p250GAP. p250GAP, also called RICS or Grit, shows GAP activity toward inhibition of RhoA, Racl, and Cdc42. p250GAP gene was recently found as a candidate gene for susceptibility to schizophrenia, suggesting its potential importance in brain development and function [189]. p250GAP is a target of microRNA 132 (miR132), which downregulates p250GAP expression and upregulates Racl activity in a manner dependent on neuronal activity. This miR132-p250GAP pathway is required for dendrite development, the hormonal regulator leptin-induced synaptogenesis, and BDNF-induced axon branching of RGCs during retinocollicular/tectal map formation [190-192]. On the other hand, p250GAP interacts with and is recruited to spines by NMDA receptors, leading to a modulation of RhoA activity and spine morphology [193, 194]. Moreover, functions of p250GAP dependent on RhoA or $\mathrm{Cdc} 42$ have been revealed in regulating neurite/axon growth and neuronal migration of cortical neurons [195197]. PX-RICS, a major isoform of p250GAP identified in the nervous system, also regulates neurite extension [198].

4.5. Rich. Rich (Rho GAP interacting with Cdc42-interacting protein 4 homologues) protein family contains two members, Rich1 and Rich2. Rich1, also called Nadrin (neuronassociated developmentally regulated protein), shows GAP activity toward RhoA, Cdc42, or Racl. In particular, Rich1 interacts with PACSIN (protein kinase $\mathrm{C}$ and casein kinase 2 substrate in neurons), a neuronal adaptor protein, to regulate dendritic spine morphogenesis through modulating Rac1 activity [199]. Different splicing variants of Rich1 have been identified in neurons and some show inhibitory effects on NGF-induced neurite outgrowth [200].

Rich2 is a novel interacting protein of Shank3, a critical postsynaptic scaffolding protein. During LTP, Rich2Shank3 interaction is increased in dendritic spines and the complex participates in exocytosis of AMPA receptor subunits through endosomal recycling [201]. Furthermore, Rich2 specifically inactivates Racl in neurons and regulates dendritic spine morphogenesis [202].

4.6. SH3BP1. An RNAi screening identified SH3BP1 (SH3domain binding protein 1) as a downstream mediator of Sema3E/PlexinD1 signaling [203]. SH3BP1 binds to PlexinD1 receptors at resting state and is released from PlexinD1 complex upon Sema3E stimulation, which in turn leads to 
inactivation of Racl and cell collapse [203]. SH3BP1 is also implicated in Sema3A-mediated growth cone collapse [204]. Moreover, an SH3BP1 splice-variant BARGIN (BGIN), which possesses a C-terminus polyubiquitin (Ub) binding module, inactivates Racl in a poly-Ub-interaction dependent manner. BGIN-mediated Racl inhibition contributes to diminishing reactive oxygen species (ROS) in APP-related pathology of $\mathrm{AD}$ [205].

4.7. CrGAP/Vilse. CrossGAP (crGAP), also called Vilse, was identified as a Rac GAP that mediates Slit-Robo signaling in axon repulsion in Drosophila $[206,207]$. In mammals, it was recently found that crGAP/Vilse interacts with CNK2 (connector enhancer of KSR-2), a scaffold protein implicated in ID, and regulates spine morphogenesis of hippocampal neurons [208].

4.8. MgcRacGAP. MgcRacGAP is a Rac GAP implicated in cytokineses. MgcRacGAP interacts with kinesin-6, a microtubule-based motor protein, and regulates F-actin distribution and movement of migrating cortical neurons [209].

\section{Conflict of Interests}

The authors declare that no conflict of interests exists.

\section{Acknowledgments}

The authors apologize to the authors whose work could not be discussed or cited because of space limitations. This work was supported in part by the Program for New Century Excellent Talents in University of China and the National Natural Science Foundation of China (Grant nos. 81422012 and 31471046).

\section{References}

[1] E.-E. Govek, S. E. Newey, and L. Van Aelst, "The role of the Rho GTPases in neuronal development," Genes and Development, vol. 19, no. 1, pp. 1-49, 2005.

[2] T. R. Stankiewicz and D. A. Linseman, "Rho family GTPases: key players in neuronal development, neuronal survival, and neurodegeneration," Frontiers in Cellular Neuroscience, vol. 8, article 314, 2014.

[3] R. Azzarelli, T. Kerloch, and E. Pacary, "Regulation of cerebral cortex development by Rho GTPases: insights from in vivo studies," Frontiers in Cellular Neuroscience, vol. 8, article 445, 2015.

[4] J. DeGeer and N. Lamarche-Vane, "Rho GTPases in neurodegeneration diseases," Experimental Cell Research, vol. 319, no. 15, pp. 2384-2394, 2013.

[5] W. Ba, J. van der Raadt, and N. N. Kasri, "Rho GTPase signaling at the synapse: implications for intellectual disability," Experimental Cell Research, vol. 319, no. 15, pp. 2368-2374, 2013.

[6] K. Burridge and K. Wennerberg, "Rho and Rac take center stage," Cell, vol. 116, no. 2, pp. 167-179, 2004.

[7] S. J. Heasman and A. J. Ridley, "Mammalian Rho GTPases: new insights into their functions from in vivo studies," Nature Reviews Molecular Cell Biology, vol. 9, no. 9, pp. 690-701, 2008.
[8] K. L. Rossman, C. J. Der, and J. Sondek, "GEF means go: turning on Rho GTPases with guanine nucleotide-exchange factors," Nature Reviews Molecular Cell Biology, vol. 6, no. 2, pp. 167-180, 2005.

[9] N. Meller, S. Merlot, and C. Guda, "CZH proteins: a new family of Rho-GEFs," Journal of Cell Science, vol. 118, part 21, pp. 49374946, 2005.

[10] J. Tcherkezian and N. Lamarche-Vane, "Current knowledge of the large RhoGAP family of proteins," Biology of the Cell, vol. 99, no. 2, pp. 67-86, 2007.

[11] K. F. Tolias, J. G. Duman, and K. Um, "Control of synapse development and plasticity by Rho GTPase regulatory proteins," Progress in Neurobiology, vol. 94, no. 2, pp. 133-148, 2011.

[12] M. B. Miller, Y. Yan, B. A. Eipper, and R. E. Mains, "Neuronal Rho GEFs in synaptic physiology and behavior," Neuroscientist, vol. 19, no. 3, pp. 255-273, 2013.

[13] C. A. Droppelmann, D. Campos-Melo, K. Volkening, and M. J. Strong, "The emerging role of guanine nucleotide exchange factors in ALS and other neurodegenerative diseases," Frontiers in Cellular Neuroscience, vol. 8, article 282, 2014.

[14] I. de Curtis, "Functions of Rac GTPases during neuronal development," Developmental Neuroscience, vol. 30, no. 1-3, pp. 47-58, 2007.

[15] K. F. Tolias, J. B. Bikoff, A. Burette et al., "The Racl-GEF Tiaml couples the NMDA receptor to the activity-dependent development of dendritic arbors and spines," Neuron, vol. 45, no. 4, pp. 525-538, 2005.

[16] K. F. Tolias, J. B. Bikoff, C. G. Kane, C. S. Tolias, L. Hu, and M. E. Greenberg, "The Racl guanine nucleotide exchange factor Tiaml mediates EphB receptor-dependent dendritic spine development," Proceedings of the National Academy of Sciences of the United States of America, vol. 104, no. 17, pp. 7265-7270, 2007.

[17] H. Zhang and I. G. Macara, "The polarity protein PAR-3 and TIAM1 cooperate in dendritic spine morphogenesis," Nature Cell Biology, vol. 8, no. 3, pp. 227-237, 2006.

[18] M. Benoist, R. Palenzuela, C. Rozas et al., "MAP1B-dependent $\mathrm{Rac}$ activation is required for AMPA receptor endocytosis during long-term depression," EMBO Journal, vol. 32, no. 16, pp. 2287-2299, 2013.

[19] K. Um, S. Niu, J. G. Duman et al., "Dynamic control of excitatory synapse development by a Racl GEF/GAP regulatory complex," Developmental Cell, vol. 29, no. 6, pp. 701-715, 2014.

[20] T. Kawauchi, K. Chihama, Y.-I. Nabeshima, and M. Hoshino, "The in vivo roles of STEF/Tiaml, Racl and JNK in cortical neuronal migration," The EMBO Journal, vol. 22, no. 16, pp. 4190-4201, 2003.

[21] M. Tanaka, R. Ohashi, R. Nakamura et al., "Tiam1 mediates neurite outgrowth induced by ephrin-B1 and EphA2," The EMBO Journal, vol. 23, no. 5, pp. 1075-1088, 2004.

[22] Y. Miyamoto, J. Yamauchi, A. Tanoue, C. Wu, and W. C. Mobley, "TrkB binds and tyrosine-phosphorylates Tiaml, leading to activation of Racl and induction of changes in cellular morphology," Proceedings of the National Academy of Sciences of the United States of America, vol. 103, no. 27, pp. 10444-10449, 2006.

[23] S. S. Fard, J. Kele, M. Vilar, G. Paratcha, and F. Ledda, “Tiam1 as a signaling mediator of Nerve Growth Factor-dependent neurite outgrowth," PLoS ONE, vol. 5, no. 3, Article ID e9647, 2010.

[24] L. Čajánek, R. S. Ganji, C. Henriques-Oliveira et al., “Tiam1 regulates the Wnt/Dvl/Racl signaling pathway and the differentiation of midbrain dopaminergic neurons," Molecular and Cellular Biology, vol. 33, no. 1, pp. 59-70, 2013. 
[25] J. Yamauchi, Y. Miyamoto, A. Tanoue, E. M. Shooter, and J. R. Chan, "Ras activation of a Racl exchange factor, Tiaml, mediates neurotrophin-3-induced Schwann cell migration," Proceedings of the National Academy of Sciences of the United States of America, vol. 102, no. 41, pp. 14889-14894, 2005.

[26] L. Xiao, C. Hu, W. Yang et al., "NMDA receptor couples RaclGEF Tiam1 to direct oligodendrocyte precursor cell migration," Glia, vol. 61, no. 12, pp. 2078-2099, 2013.

[27] R. Chandra, J. Lenz, A. M. Gancarz et al., "Optogenetic inhibition of D1R containing nucleus accumbens neurons alters cocaine-mediated regulation of Tiaml," Frontiers in Molecular Neuroscience, vol. 6, article 13, 2013.

[28] E. Blanco-Suárez, M. Fiuza, X. Liu, E. Chakkarapani, and J. G. Hanley, "Differential Tiam1/Racl activation in hippocampal and cortical neurons mediates differential spine shrinkage in response to oxygen/glucose deprivation," Journal of Cerebral Blood Flow \& Metabolism, vol. 34, no. 12, pp. 1898-1906, 2014.

[29] M. Yoshizawa, M. Hoshino, M. Sone, and Y. Nabeshima, "Expression of stef, an activator of Racl, correlates with the stages of neuronal morphological development in the mouse brain," Mechanisms of Development, vol. 113, no. 1, pp. 65-68, 2002.

[30] A. Goto, M. Hoshino, M. Matsuda, and T. Nakamura, "Phosphorylation of STEF/Tiam2 by protein kinase A is critical for Racl activation and neurite outgrowth in dibutyryl cAMPtreated PC12D cells," Molecular Biology of the Cell, vol. 22, no. 10, pp. 1780-1790, 2011.

[31] S. P. O’Brien, K. Seipel, Q. G. Medley, R. Bronson, R. Segal, and M. Streuli, "Skeletal muscle deformity and neuroanl disorder in Trio exchange factor-deficient mouse embryos," Proceedings of the National Academy of Sciences of the United States of America, vol. 97, no. 22, pp. 12074-12078, 2000.

[32] A. Briançon-Marjollet, A. Ghogha, H. Nawabi et al., "Trio mediates netrin-1-induced Racl activation in axon outgrowth and guidance," Molecular and Cellular Biology, vol. 28, no. 7, pp. 2314-2323, 2008.

[33] J. DeGeer, J. Boudeau, S. Schmidt, F. Bedford, N. LamarcheVane, and A. Debant, "Tyrosine phosphorylation of the Rho guanine nucleotide exchange factor Trio regulates netrin1/DCC-mediated cortical axon outgrowth," Molecular and Cellular Biology, vol. 33, no. 4, pp. 739-751, 2013.

[34] V. E. Neubrand, C. Thomas, S. Schmidt, A. Debant, and G. Schiavo, "Kidins220/ARMS regulates Racl-dependent neurite outgrowth by direct interaction with the RhoGEF Trio," Journal of Cell Science, vol. 123, no. 12, pp. 2111-2123, 2010.

[35] Y.-J. Sun, K. Nishikawa, H. Yuda et al., "Solo/Trio8, a membrane-associated short isoform of Trio, modulates endosome dynamics and neurite elongation," Molecular and Cellular Biology, vol. 26, no. 18, pp. 6923-6935, 2006.

[36] E. Portales-Casamar, A. Briançon-Marjollet, S. Fromont, R. Triboulet, and A. Debant, "Identification of novel neuronal isoforms of the Rho-GEF Trio," Biology of the Cell, vol. 98, no. 3, pp. 183-193, 2006.

[37] Y. J. Peng, W.-Q. He, J. Tang et al., "Trio is a key guanine nucleotide exchange factor coordinating regulation of the migration and morphogenesis of granule cells in the developing cerebellum," The Journal of Biological Chemistry, vol. 285, no. 32, pp. 24834-24844, 2010.

[38] P. Penzes, R. C. Johnson, R. Sattler et al., "The neuronal RhoGEF Kalirin-7 interacts with PDZ domain-containing proteins and regulates dendritic morphogenesis," Neuron, vol. 29, no. 1, pp. 229-242, 2001.
[39] Z. Xie, H. Photowala, M. E. Cahill et al., "Coordination of synaptic adhesion with dendritic spine remodeling by aF- 6 and kalirin-7," The Journal of Neuroscience, vol. 28, no. 24, pp. 60796091, 2008.

[40] D. D. Kiraly, K. L. Stone, C. M. Colangelo et al., "Identification of kalirin-7 as a potential post-synaptic density signaling hub," Journal of Proteome Research, vol. 10, no. 6, pp. 2828-2841, 2011.

[41] P. Penzes, A. Beeser, J. Chernoff et al., "Rapid induction of dendritic spine morphogenesis by trans-synaptic ephrinBEphB receptor activation of the Rho-GEF kalirin," Neuron, vol. 37, no. 2, pp. 263-274, 2003.

[42] Z. Xie, D. P. Srivastava, H. Photowala et al., "Kalirin-7 controls activity-dependent structural and functional plasticity of dendritic spines," Neuron, vol. 56, no. 4, pp. 640-656, 2007.

[43] K. A. Jones, D. P. Srivastava, J. A. Allen, R. T. Strachan, B. L. Roth, and P. Penzes, "Rapid modulation of spine morphology by the 5-HT2A serotonin receptor through kalirin-7 signaling," Proceedings of the National Academy of Sciences of the United States of America, vol. 106, no. 46, pp. 19575-19580, 2009.

[44] D. D. Kiraly, F. Lemtiri-Chlieh, E. S. Levine, R. E. Mains, and B. A. Eipper, "Kalirin binds the NR2B subunit of the NMDA receptor, altering its synaptic localization and function," Journal of Neuroscience, vol. 31, no. 35, pp. 12554-12565, 2011.

[45] M. E. Cahill, Z. Xie, M. Day et al., "Kalirin regulates cortical spine morphogenesis and disease-related behavioral phenotypes," Proceedings of the National Academy of Sciences of the United States of America, vol. 106, no. 31, pp. 13058-13063, 2009.

[46] Z. Xie, M. E. Cahill, J. Radulovic et al., "Hippocampal phenotypes in kalirin-deficient mice," Molecular and Cellular Neuroscience, vol. 46, no. 1, pp. 45-54, 2011.

[47] X.-M. Ma, D. D. Kiraly, E. D. Gaier et al., "Kalirin-7 is required for synaptic structure and function," Journal of Neuroscience, vol. 28, no. 47, pp. 12368-12382, 2008.

[48] A. W. Harrington, Q. M. Li, C. Tep, J. B. Park, Z. He, and S. O. Yoon, "The role of Kalirin9 in p75/Nogo receptor-mediated RhoA activation in cerebellar granule neurons," The Journal of Biological Chemistry, vol. 283, no. 36, pp. 24690-24697, 2008.

[49] A. J. Deo, M. E. Cahill, S. Li et al., "Increased expression of Kalirin-9 in the auditory cortex of schizophrenia subjects: its role in dendritic pathology," Neurobiology of Disease, vol. 45, no. 2, pp. 796-803, 2012.

[50] Y. Yan, B. A. Eipper, and R. E. Mains, "Kalirin-9 and kalirin12 play essential roles in dendritic outgrowth and branching," Cerebral Cortex, 2014.

[51] X. Xin, C. A. Rabiner, R. E. Mains, and B. A. Eipper, "Kalirin12 interacts with dynamin," BMC Neuroscience, vol. 10, article 61, 2009.

[52] C. Remmers, R. A. Sweet, and P. Penzes, "Abnormal kalirin signaling in neuropsychiatric disorders," Brain Research Bulletin, vol. 103, pp. 29-38, 2014.

[53] H. Youn, I. Ji, H. P. Ji, W. R. Markesbery, and T. H. Ji, "Underexpression of Kalirin-7 Increases iNOS activity in cultured cells and correlates to elevated iNOS activity in Alzheimer's disease hippocampus," Journal of Alzheimer's Disease, vol. 12, no. 3, pp. 271-281, 2007.

[54] H. Youn, M. Jeoung, Y. Koo et al., "Kalirin is under-expressed in Alzheimer's disease hippocampus," Journal of Alzheimer's Disease, vol. 11, no. 3, pp. 385-397, 2007.

[55] A. Hayashi-Takagi, M. Takaki, N. Graziane et al., "Disruptedin-Schizophrenia 1 (DISC1) regulates spines of the glutamate synapse via Rac1," Nature Neuroscience, vol. 13, no. 3, pp. 327$332,2010$. 
[56] M. E. Cahill, C. Remmers, K. A. Jones, Z. Xie, R. A. Sweet, and P. Penzes, "Neuregulin1 signaling promotes dendritic spine growth through kalirin," Journal of Neurochemistry, vol. 126, no. 5, pp. 625-635, 2013.

[57] M. E. Cahill, K. A. Jones, I. Rafalovich et al., "Control of interneuron dendritic growth through NRG1/erbB4-mediated kalirin-7 disinhibition," Molecular Psychiatry, vol. 17, no. 1, pp. 99-107, 2012.

[58] T. A. Russell, K. D. Blizinsky, D. J. Cobia et al., "A sequence variant in human KALRN impairs protein function and coincides with reduced cortical thickness," Nature Communications, vol. 5, article 4858, 2014.

[59] M. Beresewicz, J. E. Kowalczyk, and B. Zabłocka, "Kalirin-7, a protein enriched in postsynaptic density, is involved in ischemic signal transduction," Neurochemical Research, vol. 33, no. 9, pp. 1789-1794, 2008.

[60] X.-M. Ma, J.-P. Huang, X. Xin, Y. Yan, R. E. Mains, and B. A. Eipper, "A role for kalirin in the response of rat medium spiny neurons to cocaine," Molecular Pharmacology, vol. 82, no. 4, pp. 738-745, 2012.

[61] D. D. Kiraly, N. E. Nemirovsky, T. P. LaRese et al., "Constitutive knockout of Kalirin-7 leads to increased rates of cocaine selfadministration," Molecular Pharmacology, vol. 84, no. 4, pp. 582-590, 2013.

[62] K. Kutsche, H. Yntema, A. Brandt et al., "Mutations in ARHGEF6, encoding a guanine nucleotide exchange factor for Rho GTPases, in patients with X-linked mental retardation," Nature Genetics, vol. 26, no. 2, pp. 247-250, 2000.

[63] R. Nodé-Langlois, D. Muller, and B. Boda, "Sequential implication of the mental retardation proteins ARHGEF6 and PAK3 in spine morphogenesis," Journal of Cell Science, vol. 119, no. 23, pp. 4986-4993, 2006.

[64] G. J. A. Ramakers, D. Wolfer, G. Rosenberger et al., "Dysregulation of Rho GTPases in the $\alpha$ Pix/Arhgef6 mouse model of Xlinked intellectual disability is paralleled by impaired structural and synaptic plasticity and cognitive deficits," Human Molecular Genetics, vol. 21, no. 2, pp. 268-286, 2012.

[65] H. Zhang, D. J. Webb, H. Asmussen, S. Niu, and A. F. Horwitz, "A GIT1/PIX/Rac/PAK signaling module regulates spine morphogenesis and synapse formation through MLC," Journal of Neuroscience, vol. 25, no. 13, pp. 3379-3388, 2005.

[66] A. Totaro, S. Tavano, G. Filosa et al., "Biochemical and functional characterisation of $\alpha$ PIX, a specific regulator of axonal and dendritic branching in hippocampal neurons," Biology of the Cell, vol. 104, no. 9, pp. 533-552, 2012.

[67] M. Meseke, G. Rosenberger, and E. Förster, "Reelin and the Cdc42/Racl guanine nucleotide exchange factor $\alpha$ PIX/Arhgef6 promote dendritic Golgi translocation in hippocampal neurons," European Journal of Neuroscience, vol. 37, no. 9, pp. 14041412, 2013.

[68] E. Park, M. Na, J. Choi et al., “The Shank family of postsynaptic density proteins interacts with and promotes synaptic accumulation of the $\beta$ PIX guanine nucleotide exchange factor for Racl and Cdc42," Journal of Biological Chemistry, vol. 278, no. 21, pp. 19220-19229, 2003.

[69] T. Saneyoshi, G. Wayman, D. Fortin et al., "Activity-dependent synaptogenesis: regulation by a CaM-kinase kinase/CaMkinase I/betaPIX signaling complex," Neuron, vol. 57, no. 1, pp. 94-107, 2008.

[70] Y. Sun and S. X. Bamji, "Beta-Pix modulates actin-mediated recruitment of synaptic vesicles to synapses," The Journal of Neuroscience, vol. 31, no. 47, pp. 17123-17133, 2011.
[71] K. R. Smith, E. C. Davenport, J. Wei et al., "GIT1 and $\beta$ PIX are essential for $\mathrm{GABA}_{A}$ receptor synaptic stability and inhibitory neurotransmission," Cell Reports, vol. 9, no. 1, pp. 298-310, 2014.

[72] L. Za, C. Albertinazzi, S. Paris, M. Gagliani, C. Tacchetti, and I. de Curtis, " $\beta$ PIX controls cell motility and neurite extension by regulating the distribution of GIT1," Journal of Cell Science, vol. 119, no. 13, pp. 2654-2666, 2006.

[73] J. Mo, D. Lee, S. Hong et al., "Preso regulation of dendritic outgrowth through $\mathrm{PI}(4,5) \mathrm{P}_{2}$-dependent $\mathrm{PDZ}$ interaction with $\beta$ Pix," European Journal of Neuroscience, vol. 36, no. 1, pp. 1960 1970, 2012.

[74] K. Häbig, S. Gellhaar, B. Heim et al., "LRRK2 guides the actin cytoskeleton at growth cones together with ARHGEF7 and Tropomyosin 4," Biochimica et Biophysica Acta-Molecular Basis of Disease, vol. 1832, no. 12, pp. 2352-2367, 2013.

[75] J. Park, Y. Kim, Z. Y. Park, D. Park, and S. Chang, "Neuronal specific $\beta$ Pix-b stimulates actin-dependent processes via the interaction between its PRD and WH1 domain of N-WASP," Journal of Cellular Physiology, vol. 227, no. 4, pp. 1476-1484, 2012.

[76] L. Cheadle and T. Biederer, "Activity-dependent regulation of dendritic complexity by Semaphorin 3A through Farpl," The Journal of Neuroscience, vol. 34, no. 23, pp. 7999-8009, 2014.

[77] B. Zhuang, Y. S. Su, and S. Sockanathan, "FARP1 promotes the dendritic growth of spinal motor neuron subtypes through transmembrane Semaphorin6A and PlexinA4 signaling," Neuron, vol. 61, no. 3, pp. 359-372, 2009.

[78] T. Toyofuku, J. Yoshida, T. Sugimoto et al., "FARP2 triggers signals for Sema3A-mediated axonal repulsion," Nature Neuroscience, vol. 8, no. 12, pp. 1712-1719, 2005.

[79] G. Mlechkovich, S.-S. Peng, V. Shacham et al., "Distinct cytoplasmic domains in Plexin-A4 mediate diverse responses to semaphorin 3A in developing mammalian neurons," Science Signaling, vol. 7, no. 316, p. ra24, 2014.

[80] L. Cheadle and T. Biederer, “The novel synaptogenic protein farpl links postsynaptic cytoskeletal dynamics and transsynaptic organization," Journal of Cell Biology, vol. 199, no. 6, pp. 9851001, 2012.

[81] J. E. Waters, M. V. Astle, L. M. Ooms, D. Balamatsias, R. Gurung, and C. A. Mitchell, "P-Rexl-a multidomain protein that regulates neurite differentiation," Journal of Cell Science, vol. 121, no. 17, pp. 2892-2903, 2008.

[82] M. Yoshizawa, T. Kawauchi, M. Sone et al., "Involvement of a Rac activator, P-Rexl, in neurotrophin-derived signaling and neuronal migration," Journal of Neuroscience, vol. 25, no. 17, pp. 4406-4419, 2005.

[83] J. Dimidschstein, L. Passante, A. Dufour et al., "Ephrin-B1 controls the columnar distribution of cortical pyramidal neurons by restricting their tangential migration," Neuron, vol. 79, no. 6, pp. 1123-1135, 2013.

[84] S. Donald, T. Humby, I. Fyfe et al., "P-Rex2 regulates Purkinje cell dendrite morphology and motor coordination," Proceedings of the National Academy of Sciences of the United States of America, vol. 105, no. 11, pp. 4483-4488, 2008.

[85] C. Jackson, H. C. Welch, and T. C. Bellamy, "Control of cerebellar long-term potentiation by p-rex-family guaninenucleotide exchange factors and phosphoinositide 3-kinase," PLoS ONE, vol. 5, no. 8, Article ID e11962, 2010.

[86] K. Aoki, T. Nakamura, K. Fujikawa, and M. Matsuda, "Local phosphatidylinositol 3,4,5-trisphosphate accumulation recruits 
Vav2 and Vav3 to activate Racl/Cdc42 and initiate neurite outgrowth in nerve growth factor-stimulated PC12 cells," Molecular Biology of the Cell, vol. 16, no. 5, pp. 2207-2217, 2005.

[87] M.-S. Moon and T. M. Gomez, "Balanced Vav2 GEF activity regulates neurite outgrowth and branching in vitro and in vivo," Molecular and Cellular Neuroscience, vol. 44, no. 2, pp. 118-128, 2010.

[88] J. Angibaud, A. Louveau, S. J. Baudouin et al., "The immune molecule CD3zeta and its downstream effectors ZAP-70/Syk mediate ephrin signaling in neurons to regulate early neuritogenesis," Journal of Neurochemistry, vol. 119, no. 4, pp. 708-722, 2011.

[89] C. W. Cowan, Y. R. Shao, M. Sahin et al., "Vav family GEFs link activated Ephs to endocytosis and axon guidance," Neuron, vol. 46, no. 2, pp. 205-217, 2005.

[90] C. F. Hale, K. C. Dietz, J. A. Varela et al., "Essential role for vav guanine nucleotide exchange factors in brain-derived neurotrophic factor-induced dendritic spine growth and synapse plasticity," The Journal of Neuroscience, vol. 31, no. 35, pp. 1242612436, 2011.

[91] K. Fujikawa, T. Iwata, K. Inoue et al., "VAV2 and VAV3 as candidate disease genes for spontaneous glaucoma in mice and humans," PLoS ONE, vol. 5, no. 2, Article ID e9050, 2010.

[92] G. Keilhoff, S. Wiegand, and H. Fansa, "Vav deficiency impedes peripheral nerve regeneration in mice," Restorative Neurology and Neuroscience, vol. 30, no. 6, pp. 463-479, 2012.

[93] C. Quevedo, V. Sauzeau, M. Menacho-Márquez, A. CastroCastro, and X. R. Bustelo, "Vav3-deficient mice exhibit a transient delay in cerebellar development," Molecular Biology of the Cell, vol. 21, no. 6, pp. 1125-1139, 2010.

[94] V. Sauzeau, J. A. C. Horta-Junior, A. S. Riolobos et al., "Vav3 is involved in GABAergic axon guidance events important for the proper function of brainstem neurons controlling cardiovascular, respiratory, and renal parameters," Molecular Biology of the Cell, vol. 21, no. 23, pp. 4251-4263, 2010.

[95] B. Aleksic, I. Kushima, R. Hashimoto et al., "Analysis of the VAV3 as candidate gene for schizophrenia: evidences from voxel-based morphometry and mutation screening," Schizophrenia Bulletin, vol. 39, no. 3, pp. 720-728, 2013.

[96] K. Ishikawa, S. Toru, T. Tsunemi et al., "An autosomal dominant cerebellar ataxia linked to chromosome 16q22.1 is associated with a single-nucleotide substitution in the $5^{\prime}$ untranslated region of the gene encoding a protein with spectrin repeat and Rho guanine-nucleotide exchange-factor domains," The American Journal of Human Genetics, vol. 77, no. 2, pp. 280-296, 2005.

[97] M. Gupta, E. Kamynina, S. Morley et al., "Plekhg4 is a novel Dbl family guanine nucleotide exchange factor protein for rho family GTPases," The Journal of Biological Chemistry, vol. 288, no. 20, pp. 14522-14530, 2013.

[98] B. Bryan, V. Kumar, L. J. Stafford, Y. Cai, G. Wu, and M. Liu, "GEFT, a Rho family guanine nucleotide exchange factor, regulates neurite outgrowth and dendritic spine formation," Journal of Biological Chemistry, vol. 279, no. 44, pp. 45824-45832, 2004.

[99] B. A. Bryan, Y. Cai, and M. Liu, "The Rho-family guanine nucleotide exchange factor GEFT enhances retinoic acid- and cAMP-induced neurite outgrowth," Journal of Neuroscience Research, vol. 83, no. 7, pp. 1151-1159, 2006.

[100] L. A. Feig, "Regulation of neuronal function by Ras-GRF exchange factors," Genes and Cancer, vol. 2, no. 3, pp. 306-319, 2011.
[101] A. Fernández-Medarde and E. Santos, “The RasGrf family of mammalian guanine nucleotide exchange factors," Biochimica et Biophysica Acta, vol. 1815, no. 2, pp. 170-188, 2011.

[102] S. Li, X. Tian, D. M. Hartley, and L. A. Feig, "Distinct roles for Ras-guanine nucleotide-releasing factor 1 (Ras-GRF1) and RasGRF2 in the induction of long-term potentiation and long-term depression," Journal of Neuroscience, vol. 26, no. 6, pp. 1721-1729, 2006.

[103] M. J. Darcy, S. Trouche, S.-X. Jin, and L. A. Feig, "Age-dependent role for Ras-GRF1 in the late stages of adult neurogenesis in the dentate gyrus," Hippocampus, vol. 24, no. 3, pp. 315-325, 2014.

[104] G. Krapivinsky, L. Krapivinsky, Y. Manasian et al., "The NMDA receptor is coupled to the ERK pathway by a direct interaction between NR2B and RasGRF1," Neuron, vol. 40, no. 4, pp. 775784, 2003.

[105] F. J. Sepulveda, F. J. Bustos, E. Inostroza et al., "Differential roles of NMDA receptor subtypes NR2A and NR2B in dendritic branch development and requirement of RasGRF1," Journal of Neurophysiology, vol. 103, no. 4, pp. 1758-1770, 2010.

[106] S. X. Jin and L. A. Feig, "Long-term potentiation in the CA1 hippocampus induced by NR2A subunit-containing NMDA glutamate receptors is mediated by Ras-GRF2/Erk map kinase signaling," PLoS ONE, vol. 5, no. 7, Article ID e11732, 2010.

[107] K. P. Giese, E. Friedman, J.-B. Telliez et al., "Hippocampusdependent learning and memory is impaired in mice lacking the Ras-guanine-nucleotide releasing factor 1 (Ras-GRF1)," Neuropharmacology, vol. 41, no. 6, pp. 791-800, 2001.

[108] S. Fasano, A. D’Antoni, P. C. Orban et al., "Ras-guanine nucleotide-releasing factor 1 (Ras-GRF1) controls activation of extracellular signal-regulated kinase (ERK) signaling in the striatum and long-term behavioral responses to cocaine," Biological Psychiatry, vol. 66, no. 8, pp. 758-768, 2009.

[109] N. K. Parelkar, Q. Jiang, X.-P. Chu, M.-L. Guo, L.-M. Mao, and J. Q. Wang, "Amphetamine alters Ras-guanine nucleotidereleasing factor expression in the rat striatum in vivo," European Journal of Pharmacology, vol. 619, no. 1-3, pp. 50-56, 2009.

[110] S. Fasano, E. Bezard, A. D’Antoni et al., "Inhibition of Rasguanine nucleotide-releasing factor 1 (Ras-GRF1) signaling in the striatum reverts motor symptoms associated with L-dopainduced dyskinesia," Proceedings of the National Academy of Sciences of the United States of America, vol. 107, no. 50, pp. 21824-21829, 2010.

[111] Q. Zhu, L. Wang, Z. Xiao et al., "Decreased expression of RasGRF1 in the brain tissue of the intractable epilepsy patients and experimental rats," Brain Research, vol. 1493, pp. 99-109, 2013.

[112] M. Cerovic, V. Bagetta, V. Pendolino et al., "Derangement of Ras-Guanine Nucleotide-Releasing Factor 1 (Ras-GRF1) and Extracellular Signal-Regulated Kinase (ERK) Dependent Striatal Plasticity in L-DOPA-Induced Dyskinesia," Biological Psychiatry, vol. 77, no. 2, pp. 106-115, 2015.

[113] D. Stacey, A. Bilbao, M. Maroteaux et al., "RASGRF2 regulates alcohol-induced reinforcement by influencing mesolimbic dopamine neuron activity and dopamine release," Proceedings of the National Academy of Sciences of the United States of America, vol. 109, no. 51, pp. 21128-21133, 2012.

[114] M. J. Darcy, S. Trouche, S.-X. Jin, and L. A. Feig, "Ras-GRF2 mediates long-term potentiation, survival, and response to an enriched environment of newborn neurons in the hippocampus," Hippocampus, vol. 24, no. 11, pp. 1317-1329, 2014.

[115] B. Schwechter, C. Rosenmund, and K. F. Tolias, "RasGRF2 RacGEF activity couples NMDA receptor calcium flux to enhanced 
synaptic transmission," Proceedings of the National Academy of Sciences of the United States of America, vol. 110, no. 35, pp. 14462-14467, 2013.

[116] S. Baldassa, N. Gnesutta, U. Fascio, E. Sturani, and R. Zippel, "SCLIP, a microtubule-destabilizing factor, interacts with RasGRF1 and inhibits its ability to promote Rac activation and neurite outgrowth," The Journal of Biological Chemistry, vol. 282, no. 4, pp. 2333-2345, 2007.

[117] S. Kesavapany, N. Amin, Y.-L. Zheng et al., "p35/cyclindependent kinase 5 phosphorylation of ras guanine nucleotide releasing factor 2 (RasGRF2) mediates Rac-dependent Extracellular Signal-regulated kinase 1/2 activity, altering RasGRF2 and microtubule-associated protein $1 \mathrm{~b}$ distribution in neurons," The Journal of Neuroscience, vol. 24, no. 18, pp. 4421-4431, 2004.

[118] H. Cai, H. Shim, C. Lai et al., "ALS2/alsin knockout mice and motor neuron diseases," Neurodegenerative Diseases, vol. 5, no. 6, pp. 359-366, 2008.

[119] E. L. Tudor, M. S. Perkinton, A. Schmidt et al., "ALS2/Alsin regulates Rac-PAK signaling and neurite outgrowth," The Journal of Biological Chemistry, vol. 280, no. 41, pp. 34735-34740, 2005.

[120] K. Kanekura, Y. Hashimoto, Y. Kita et al., "A Racl/ phosphatidylinositol 3-kinase/Akt3 anti-apoptotic pathway, triggered by alsinLF, the product of the ALS2 gene, antagonizes $\mathrm{Cu} / \mathrm{Zn}$-superoxide dismutase (SOD1) mutant-induced motoneuronal cell death," The Journal of Biological Chemistry, vol. 280, no. 6, pp. 4532-4543, 2005.

[121] A. Jacquier, E. Buhler, M. K. E. Schäfer et al., "Alsin/Rac1 signaling controls survival and growth of spinal motoneurons," Annals of Neurology, vol. 60, no. 1, pp. 105-117, 2006.

[122] C. Lai, C. Xie, S. G. McCormack et al., "Amyotrophic lateral sclerosis 2-deficiency leads to neuronal degeneration in amyotrophic lateral sclerosis through altered AMPA receptor trafficking," The Journal of Neuroscience, vol. 26, no. 45, pp. 11798-11806, 2006.

[123] R. S. Devon, P. C. Orban, K. Gerrow et al., "Als2-deficient mice exhibit disturbances in endosome trafficking associated with motor behavioral abnormalities," Proceedings of the National Academy of Sciences of the United States of America, vol. 103, no. 25, pp. 9595-9600, 2006.

[124] C. Lai, C. Xie, H. Shim, J. Chandran, B. W. Howell, and H. Cai, "Regulation of endosomal motility and degradation by amyotrophic lateral sclerosis 2/alsin," Molecular Brain, vol. 2, no. 1, article 23, 2009.

[125] R. Kunita, A. Otomo, H. Mizumura, K. Suzuki-Utsunomiya, S. Hadano, and J.-E. Ikeda, "The Rab5 activator ALS2/alsin acts as a novel Racl effector through Racl-activated endocytosis," The Journal of Biological Chemistry, vol. 282, no. 22, pp. 16599-16611, 2007.

[126] A. Otomo, R. Kunita, K. Suzuki-Utsunomiya, J.-E. Ikeda, and S. Hadano, "Defective relocalization of ALS2/alsin missense mutants to Racl-induced macropinosomes accounts for loss of their cellular function and leads to disturbed amphisome formation," FEBS Letters, vol. 585, no. 5, pp. 730-736, 2011.

[127] K. Kanekura, Y. Hashimoto, T. Niikura, S. Aiso, M. Matsuoka, and I. Nishimoto, "Alsin, the product of ALS2 gene, suppresses SOD1 mutant neurotoxicity through RhoGEF domain by interacting with SOD1 mutants," Journal of Biological Chemistry, vol. 279, no. 18, pp. 19247-19256, 2004.

[128] S. Hadano, A. Otomo, R. Kunita et al., "Loss of ALS2/Alsin exacerbates motor dysfunction in a $\mathrm{SOD1}^{H 46 R}$-expressing mouse ALS model by disturbing endolysosomal trafficking," PLoS ONE, vol. 5, no. 3, Article ID e9805, 2010.
[129] L. Shi, "Dock protein family in brain development and neurological disease," Communicative and Integrative Biology, vol. 6, no. 6, Article ID e26839, 2013.

[130] X. Li, X. Gao, G. Liu, W. Xiong, J. Wu, and Y. Rao, "Netrin signal transduction and the guanine nucleotide exchange factor DOCK180 in attractive signaling," Nature Neuroscience, vol. 11, no. 1, pp. 28-35, 2008.

[131] N.-J. Xu and M. Henkemeyer, "Ephrin-B3 reverse signaling through Grb4 and cytoskeletal regulators mediates axon pruning," Nature Neuroscience, vol. 12, no. 3, pp. 268-276, 2009.

[132] K. Franke, W. Otto, S. Johannes, J. Baumgart, R. Nitsch, and S. Schumacher, "miR-124-regulated RhoG reduces neuronal process complexity via ELMO/Dock180/Racl and Cdc42 signalling," EMBO Journal, vol. 31, no. 13, pp. 2908-2921, 2012.

[133] J.-Y. Kim, M. H. Oh, L. P. Bernard, I. G. Macara, and H. Zhang, "The RhoG/ELMO1/Dock180 signaling module is required for spine morphogenesis in hippocampal neurons," The Journal of Biological Chemistry, vol. 286, no. 43, pp. 37615-37624, 2011.

[134] P. J. Cimino, I. Sokal, J. Leverenz, Y. Fukui, and T. J. Montine, "DOCK2 is a microglial specific regulator of central nervous system innate immunity found in normal and Alzheimer's disease brain," American Journal of Pathology, vol. 175, no. 4, pp. 1622-1630, 2009.

[135] P. J. Cimino, Y. Yang, X. Li et al., "Ablation of the microglial protein DOCK2 reduces amyloid burden in a mouse model of Alzheimer's disease," Experimental and Molecular Pathology, vol. 94, no. 2, pp. 366-371, 2013.

[136] K. Namekata, A. Kimura, K. Kawamura, C. Harada, and T. Harada, "Dock GEFs and their therapeutic potential: neuroprotection and axon regeneration," Progress in Retinal and Eye Research, vol. 43, pp. 1-16, 2014.

[137] Q. Chen, T. J. Chen, P. C. Letourneau, L. D. F. Costa, and D. Schubert, "Modifier of cell adhesion regulates N-cadherinmediated cell-cell adhesion and neurite outgrowth," The Journal of Neuroscience, vol. 25, no. 2, pp. 281-290, 2005.

[138] K. Namekata, C. Harada, C. Taya et al., "Dock3 induces axonal outgrowth by stimulating membrane recruitment of the WAVE complex," Proceedings of the National Academy of Sciences of the United States of America, vol. 107, no. 16, pp. 7586-7591, 2010.

[139] Q. Chen, C. A. Peto, G. D. Shelton, A. Mizisin, P. E. Sawchenko, and D. Schubert, "Loss of modifier of cell adhesion reveals a pathway leading to axonal degeneration," Journal of Neuroscience, vol. 29, no. 1, pp. 118-130, 2009.

[140] Q. Chen, H. Kimura, and D. Schubert, "A novel mechanism for the regulation of amyloid precursor protein metabolism," The Journal of Cell Biology, vol. 158, no. 1, pp. 79-89, 2002.

[141] N. Bai, H. Hayashi, T. Aida et al., "Dock3 interaction with a glutamate-receptor NR2D subunit protects neurons from excitotoxicity," Molecular Brain, vol. 6, no. 1, article 22, 2013.

[142] K. Namekata, A. Kimura, K. Kawamura et al., "Dock3 attenuates neural cell death due to NMDA neurotoxicity and oxidative stress in a mouse model of normal tension glaucoma," Cell Death and Differentiation, vol. 20, no. 9, pp. 1250-1256, 2013.

[143] K. Namekata, A. Kimura, C. Harada, H. Yoshida, Y. Matsumoto, and T. Harada, "Dock3 protects myelin in the cuprizone model for demyelination," Cell Death and Disease, vol. 5, no. 8, Article ID e1395, 2014.

[144] K. Semba, K. Namekata, A. Kimura et al., "Dock3 overexpression and p38 MAPK inhibition synergistically stimulate neuroprotection and axon regeneration after optic nerve injury," Neuroscience Letters, vol. 581, pp. 89-93, 2014. 
[145] A. T. Pagnamenta, E. Bacchelli, M. V. de Jonge et al., "Characterization of a family with rare deletions in CNTNAP5 and DOCK4 suggests novel risk loci for autism and dyslexia," Biological Psychiatry, vol. 68, no. 4, pp. 320-328, 2010.

[146] E. Maestrini, A. T. Pagnamenta, J. A. Lamb et al., "High-density SNP association study and copy number variation analysis of the AUTS1 and AUTS5 loci implicate the IMMP2L-DOCK4 gene region in autism susceptibility," Molecular Psychiatry, vol. 15, no. 9, pp. 954-968, 2010.

[147] A. Alkelai, S. Lupoli, L. Greenbaum et al., "DOCK4 and CEACAM21 as novel schizophrenia candidate genes in the Jewish population," International Journal of Neuropsychopharmacology, vol. 15, no. 4, pp. 459-469, 2012.

[148] Y. Xiao, Y. Peng, J. Wan et al., "The atypical guanine nucleotide exchange factor Dock4 regulates neurite differentiation through modulation of Racl GTPase and actin dynamics," Journal of Biological Chemistry, vol. 288, no. 27, pp. 20034-20045, 2013.

[149] S. Ueda, M. Negishi, and H. Katoh, "Rac GEF dock4 interacts with cortactin to regulate dendritic spine formation," Molecular Biology of the Cell, vol. 24, no. 10, pp. 1602-1613, 2013.

[150] Y. Miyamoto, J. Yamauchi, A. Sanbe, and A. Tanoue, "Dock6, a Dock-C subfamily guanine nucleotide exchanger, has the dual specificity for Racl and Cdc42 and regulates neurite outgrowth," Experimental Cell Research, vol. 313, no. 4, pp. 791-804, 2007.

[151] Y. Miyamoto, T. Torii, N. Yamamori, T. Ogata, A. Tanoue, and J. Yamauchi, "Akt and PP2A reciprocally regulate the guanine nucleotide exchange factor Dock6 to control axon growth of sensory neurons," Science Signaling, vol. 6, no. 265, article ra15, 2013.

[152] M. Watabe-Uchida, K. A. John, J. A. Janas, S. E. Newey, and L. Van Aelst, "The Rac activator DOCK7 regulates neuronal polarity through local phosphorylation of stathmin/Op18," Neuron, vol. 51, no. 6, pp. 727-739, 2006.

[153] Y.-T. Yang, C.-L. Wang, and L. Van Aelst, "DOCK7 interacts with TACC3 to regulate interkinetic nuclear migration and cortical neurogenesis," Nature Neuroscience, vol. 15, no. 9, pp. 1201-1210, 2012.

[154] Y. Tai, J. A. Janas, C.-L. Wang, and L. Van Aelst, "Regulation of chandelier cell cartridge and bouton development via DOCK7mediated ErbB4 activation," Cell Reports, vol. 6, no. 2, pp. 254263, 2014.

[155] I. Perrault, F. F. Hamdan, M. Rio et al., "Mutations in DOCK7 in individuals with epileptic encephalopathy and cortical blindness," The American Journal of Human Genetics, vol. 94, no. 6, pp. 891-897, 2014.

[156] J. Yamauchi, Y. Miyamoto, H. Hamasaki et al., "The atypical Guanine-nucleotide exchange factor, dock7, negatively regulates schwann cell differentiation and myelination," Journal of Neuroscience, vol. 31, no. 35, pp. 12579-12592, 2011.

[157] J. Yamauchi, Y. Miyamoto, J. R. Chan, and A. Tanoue, "ErbB2 directly activates the exchange factor Dock7 to promote Schwann cell migration," Journal of Cell Biology, vol. 181, no. 2, pp. 351-365, 2008.

[158] D. Oh, S. Han, J. Seo et al., "Regulation of synaptic Racl activity, long-term potentiation maintenance, and learning and memory by BCR and ABR Rac GTPase-activating proteins," The Journal of Neuroscience, vol. 30, no. 42, pp. 14134-14144, 2010.

[159] V. Kaartinen, I. Gonzalez-Gomez, J. W. Voncken et al., "Abnormal function of astroglia lacking Abr and Bcr RacGAPs," Development, vol. 128, no. 21, pp. 4217-4227, 2001.
[160] A.-R. Park, D. Oh, S.-H. Lim et al., "Regulation of dendritic arborization by BCR Racl GTPase-activating protein, a substrate of PTPRT," Journal of Cell Science, vol. 125, no. 19, pp. 4518-4531, 2012.

[161] C. Yang and M. G. Kazanietz, "Chimaerins: GAPs that bridge diacylglycerol signalling and the small G-protein Rac," The Biochemical Journal, vol. 403, no. 1, pp. 1-12, 2007.

[162] N. Miyake, J. Chilton, M. Psatha et al., "Human CHN1 mutations hyperactivate alpha2-chimaerin and cause Duane's retraction syndrome," Science, vol. 321, no. 5890, pp. 839-843, 2008.

[163] J. E. Ferrario, P. Baskaran, C. Clark et al., "Axon guidance in the developing ocular motor system and Duane retraction syndrome depends on Semaphorin signaling via alpha2chimaerin," Proceedings of the National Academy of Sciences of the United States of America, vol. 109, no. 36, pp. 14669-14674, 2012.

[164] H. Wegmeyer, J. Egea, N. Rabe et al., "EphA4-dependent axon guidance is mediated by the RacGAP $\alpha 2$-chimaerin," Neuron, vol. 55, no. 5, pp. 756-767, 2007.

[165] L. Shi, W.-Y. Fu, K.-W. Hung et al., " $\alpha 2$-Chimaerin interacts with EphA4 and regulates EphA4-dependent growth cone collapse," Proceedings of the National Academy of Sciences of the United States of America, vol. 104, no. 41, pp. 16347-16352, 2007.

[166] A. A. Beg, J. E. Sommer, J. H. Martin, and P. Scheiffele, "alpha2Chimaerin is an essential EphA4 effector in the assembly of neuronal locomotor circuits," Neuron, vol. 55, no. 5, pp. 768778, 2007.

[167] T. Iwasato, H. Katoh, H. Nishimaru et al., "Rac-GAP $\alpha$ chimerin regulates motor-circuit formation as a key mediator of EphrinB3/EphA4 forward signaling," Cell, vol. 130, no. 4, pp. 742-753, 2007.

[168] C. O. Asante, A. Chu, M. Fisher et al., "Cortical control of adaptive locomotion in wild-type mice and mutant mice lacking the ephrin-Eph effector protein alpha2-chimaerin," Journal of Neurophysiology, vol. 104, no. 6, pp. 3189-3202, 2010.

[169] J. P. Fawcett, J. Georgiou, J. Ruston et al., "Nck adaptor proteins control the organization of neuronal circuits important for walking," Proceedings of the National Academy of Sciences of the United States of America, vol. 104, no. 52, pp. 20973-20978, 2007.

[170] R. Iwata, K. Ohi, Y. Kobayashi et al., "RacGAP alpha2-chimaerin function in development adjusts cognitive ability in adulthood," Cell Reports, vol. 8, no. 5, pp. 1257-1264, 2014.

[171] J. P. K. Ip, L. Shi, Y. Chen et al., "alpha2-chimaerin controls neuronal migration and functioning of the cerebral cortex through CRMP-2," Nature Neuroscience, vol. 15, no. 1, pp. 3947, 2012.

[172] T. J. van de Ven, H. M. A. VanDongen, and A. M. J. VanDongen, "The nonkinase phorbol ester receptor $\alpha 1$-chimerin binds the NMDA receptor NR2A subunit and regulates dendritic spine density," The Journal of Neuroscience, vol. 25, no. 41, pp. 94889496, 2005.

[173] P. Buttery, A. A. Beg, B. Chih, A. Broder, C. A. Mason, and P. Scheiffele, "The diacylglycerol-binding protein alphalchimaerin regulates dendritic morphology," Proceedings of the National Academy of Sciences of the United States of America, vol. 103, no. 6, pp. 1924-1929, 2006.

[174] M. M. Riccomagno, A. Hurtado, H. Wang et al., “The RacGAP $\beta 2$-chimaerin selectively mediates axonal pruning in the hippocampus," Cell, vol. 149, no. 7, pp. 1594-1606, 2012. 
[175] D. L. Vogt, C. D. Gray, W. S. Young III, S. A. Orellana, and A. T. Malouf, "ARHGAP4 is a novel RhoGAP that mediates inhibition of cell motility and axon outgrowth," Molecular and Cellular Neuroscience, vol. 36, no. 3, pp. 332-342, 2007.

[176] S. Guerrier, J. Coutinho-Budd, T. Sassa et al., "The F-BAR domain of srGAP2 induces membrane protrusions required for neuronal migration and morphogenesis," Cell, vol. 138, no. 5, pp. 990-1004, 2009.

[177] C. Charrier, K. Joshi, J. Coutinho-Budd et al., "Inhibition of SRGAP2 function by its human-specific paralogs induces neoteny during spine maturation," Cell, vol. 149, no. 4, pp. 923935, 2012.

[178] M. Y. Dennis, X. Nuttle, P. H. Sudmant et al., "Evolution of human-specific neural SRGAP2 genes by incomplete segmental duplication," Cell, vol. 149, no. 4, pp. 912-922, 2012.

[179] V. Endris, B. Wogatzky, U. Leimer et al., “The novel Rho-GTPase activating gene MEGAP/srGAP3 has a putative role in severe mental retardation," Proceedings of the National Academy of Sciences of the United States of America, vol. 99, no. 18, pp. 1175411759, 2002.

[180] B. R. Carlson, K. E. Lloyd, A. Kruszewski et al., "WRP/srGAP3 facilitates the initiation of spine development by an inverse FBAR domain, and its loss impairs long-term memory," Journal of Neuroscience, vol. 31, no. 7, pp. 2447-2460, 2011.

[181] R. Waltereit, U. Leimer, O. von Bohlen Und Halbach et al., "Srgap $3^{-/-}$mice present a neurodevelopmental disorder with schizophrenia-related intermediate phenotypes," The FASEB Journal, vol. 26, no. 11, pp. 4418-4428, 2012.

[182] S. H. Soderling, E. S. Guire, S. Kaech et al., "A WAVE-1 and WRP signaling complex regulates spine density, synaptic plasticity, and memory," Journal of Neuroscience, vol. 27, no. 2, pp. 355$365,2007$.

[183] I. H. Kim, B. R. Carlson, C. C. Heindel, H. Kim, and S. H. zSoderling, "Disruption of wave-associated Rac GTPaseactivating protein (Wrp) leads to abnormal adult neural progenitor migration associated with hydrocephalus," The Journal of Biological Chemistry, vol. 287, no. 46, pp. 39263-39274, 2012.

[184] K. Chen, Y.-J. Mi, Y. Ma, H.-L. Fu, and W.-L. Jin, “The mental retardation associated protein, srGAP3 negatively regulates VPA-induced neuronal differentiation of Neuro2A cells," Cellular and Molecular Neurobiology, vol. 31, no. 5, pp. 675-686, 2011.

[185] H. Lu, Q. Jiao, Y. Wang et al., "The mental retardationassociated protein srGAP3 regulates survival, proliferation, and differentiation of rat embryonic neural stem/progenitor cells," Stem Cells and Development, vol. 22, no. 11, pp. 1709-1716, 2013.

[186] Y. Ma, Y.-J. Mi, Y.-K. Dai, H.-L. Fu, D.-X. Cui, and W.-L. Jin, "The inverse F-BAR domain protein srGAP2 acts through srGAP3 to modulate neuronal differentiation and neurite outgrowth of mouse neuroblastoma cells," PLoS ONE, vol. 8, no. 3, Article ID e57865, 2013.

[187] Y.-K. Dai, Y. Ma, K. Chen et al., "A link between the nuclearlocalized srGAP3 and the SWI/SNF chromatin remodeler Brgl," Molecular and Cellular Neuroscience, vol. 60, pp. 10-25, 2014.

[188] C. Bacon, V. Endris, I. Andermatt et al., "Evidence for a role of SRGAP3 in the positioning of commissural axons within the ventrolateral funiculus of the mouse spinal cord," PLOS ONE, vol. 6, no. 5, Article ID e19887, 2011.

[189] K. Ohi, R. Hashimoto, T. Nakazawa et al., “The p250GAP gene is associated with risk for schizophrenia and schizotypal personality traits," PLoS ONE, vol. 7, no. 4, Article ID e35696, 2012.

[190] G. A. Wayman, M. Davare, H. Ando et al., "An activity-regulated microRNA controls dendritic plasticity by down-regulating
p250GAP," Proceedings of the National Academy of Sciences of the United States of America, vol. 105, no. 26, pp. 9093-9098, 2008.

[191] M. Dhar, M. Zhu, S. Impey et al., "Leptin induces hippocampal synaptogenesis via CREB-regulated microRNA-132 suppression of p250GAP," Molecular Endocrinology, vol. 28, no. 7, pp. 10731087, 2014.

[192] K. J. Marler, P. Suetterlin, A. Dopplapudi et al., "BDNF promotes axon branching of retinal ganglion cells via miRNA-132 and p250GAP," Journal of Neuroscience, vol. 34, no. 3, pp. 969-979, 2014.

[193] T. Nakazawa, A. M. Watabe, T. Tezuka et al., "p250GAP, a novel brain-enriched GTPase-activating protein for Rho family GTPases, is involved in the N-methyl-D-aspartate receptor signaling," Molecular Biology of the Cell, vol. 14, no. 7, pp. 29212934, 2003.

[194] T. Nakazawa, T. Kuriu, T. Tezuka, H. Umemori, S. Okabe, and T. Yamamoto, "Regulation of dendritic spine morphology by an NMDA receptor-associated Rho GTPase-activating protein, p250GAP," Journal of Neurochemistry, vol. 105, no. 4, pp. 13841393, 2008.

[195] Y. Nasu-Nishimura, T. Hayashi, T. Ohishi et al., "Role of the Rho GTPase-activating protein RICS in neurite outgrowth," Genes to Cells, vol. 11, no. 6, pp. 607-614, 2006.

[196] M. Kannan, S.-J. Lee, N. Schwedhelm-Domeyer, T. Nakazawa, and J. Stegmüller, " p250GAP is a novel player in the Cdh1APC/Smurf1 pathway of axon growth regulation," PLoS ONE, vol. 7, no. 11, Article ID e50735, 2012.

[197] H. Long, X. Zhu, P. Yang, Q. Gao, Y. Chen, and L. Ma, "Myo9b and RICS modulate dendritic morphology of cortical neurons," Cerebral Cortex, vol. 23, no. 1, pp. 71-79, 2013.

[198] T. Hayashi, T. Okabe, Y. Nasu-Nishimura et al., "PX-RICS, a novel splicing variant of RICS, is a main isoform expressed during neural development," Genes to Cells, vol. 12, no. 8, pp. 929-939, 2007.

[199] S. Schael, J. Nüchel, S. Müller et al., "Casein kinase 2 phosphorylation of protein kinase $\mathrm{C}$ and casein kinase 2 substrate in neurons (PACSIN) 1 protein regulates neuronal spine formation," Journal of Biological Chemistry, vol. 288, no. 13, pp. 9303-9312, 2013.

[200] B. Furuta, A. Harada, Y. Kobayashi, K.-I. Takeuchi, T. Kobayashi, and M. Umeda, "Identification and functional characterization of nadrin variants, a novel family of GTPase activating protein for rho GTPases," Journal of Neurochemistry, vol. 82, no. 5, pp. 1018-1028, 2002.

[201] F. Raynaud, A. Janossy, J. Dahl et al., "Shank3-Rich2 interaction regulates AMPA receptor recycling and synaptic long-term potentiation," The Journal of Neuroscience, vol. 33, no. 23, pp. 9699-9715, 2013.

[202] F. Raynaud, E. Moutin, S. Schmidt et al., "Rho-GTPaseactivating protein interacting with Cdc-42-interacting protein 4 homolog 2 (Rich2): a new ras-related C3 botulinum toxin substratel (Racl) GTPase-activating protein that controls dendritic spine morphogenesis," Journal of Biological Chemistry, vol. 289, no. 5, pp. 2600-2609, 2014.

[203] A. Tata, D. C. Stoppel, S. Hong, A. Ben-Zvi, T. Xie, and C. $\mathrm{Gu}$, "An image-based RNAi screen identifies SH3BP1 as a key effector of Semaphorin 3E-PlexinD1 signaling," The Journal of Cell Biology, vol. 205, no. 4, pp. 573-590, 2014.

[204] I. Västrik, B. J. Eickholt, F. S. Walsh, A. Ridley, and P. Doherty, "Sema3A-induced growth-cone collapse is mediated by Rac1 
amino acids 17-32," Current Biology, vol. 9, no. 18, pp. 991-998, 1999.

[205] T. Y. Huang, S. Michael, T. Xu et al., "A novel Racl GAP splice variant relays poly-Ub accumulation signals to mediate Racl inactivation," Molecular Biology of the Cell, vol. 24, no. 3, pp. 194-209, 2013.

[206] A. Lundström, M. Gallio, C. Englund et al., "Vilse, a conserved Rac/Cdc42 GAP mediating Robo repulsion in tracheal cells and axons," Genes and Development, vol. 18, no. 17, pp. 2161-2171, 2004.

[207] H. Hu, M. Li, J.-P. Labrador et al., "Cross GTPase-activating protein (CrossGAP)/Vilse links the Roundabout receptor to Rac to regulate midline repulsion," Proceedings of the National Academy of Sciences of the United States of America, vol. 102, no. 12, pp. 4613-4618, 2005.

[208] J. Lim, D. A. Ritt, M. Zhou, and D. K. Morrison, “The CNK2 scaffold interacts with vilse and modulates rac cycling during spine morphogenesis in hippocampal neurons," Current Biology, vol. 24, no. 7, pp. 786-792, 2014.

[209] A. Falnikar, S. Tole, M. Liu, J. S. Liu, and P. W. Baas, "Polarity in migrating neurons is related to a mechanism analogous to cytokinesis," Current Biology, vol. 23, no. 13, pp. 1215-1220, 2013. 

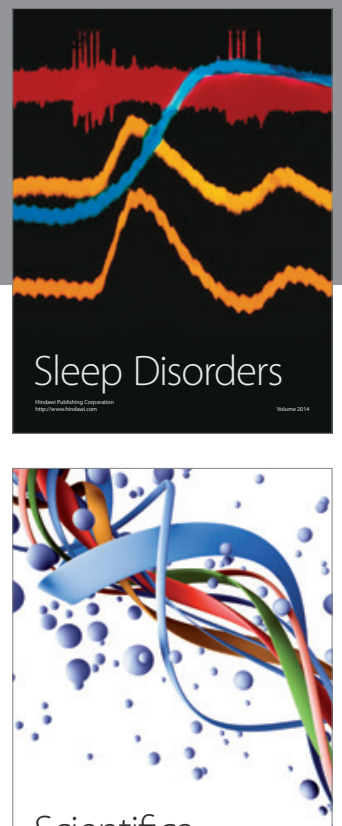

Scientifica
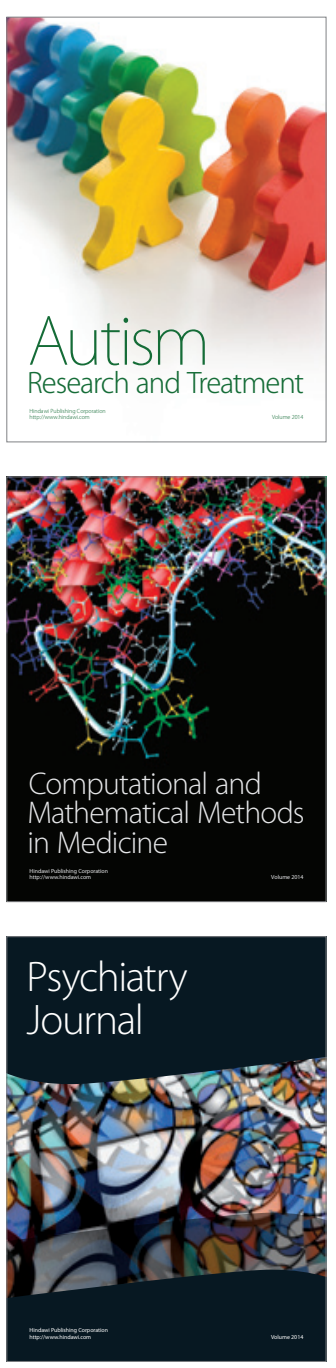
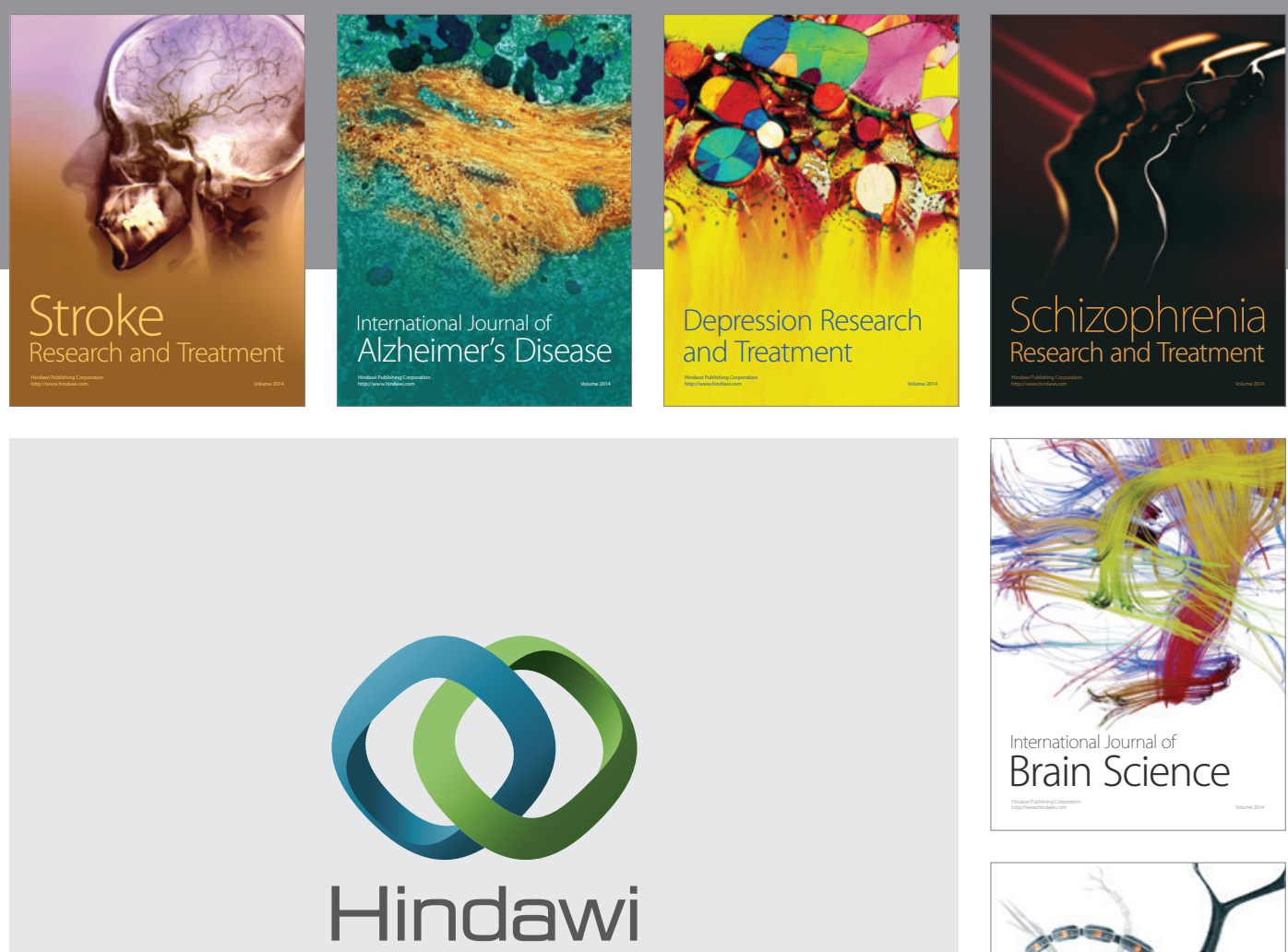

Submit your manuscripts at

http://www.hindawi.com
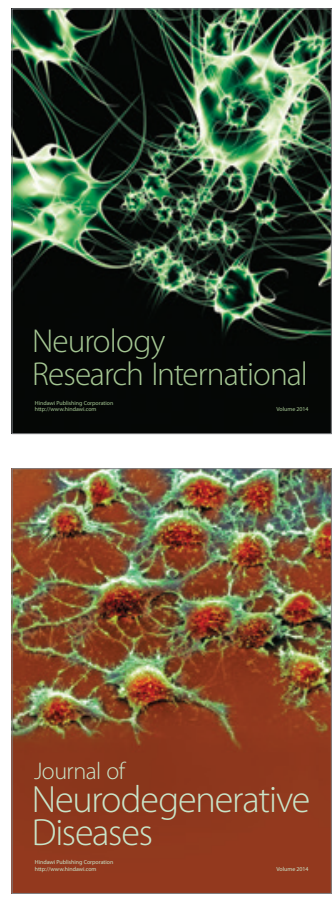

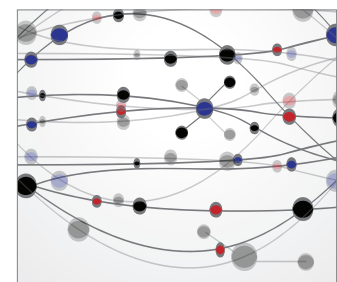

The Scientific World Journal
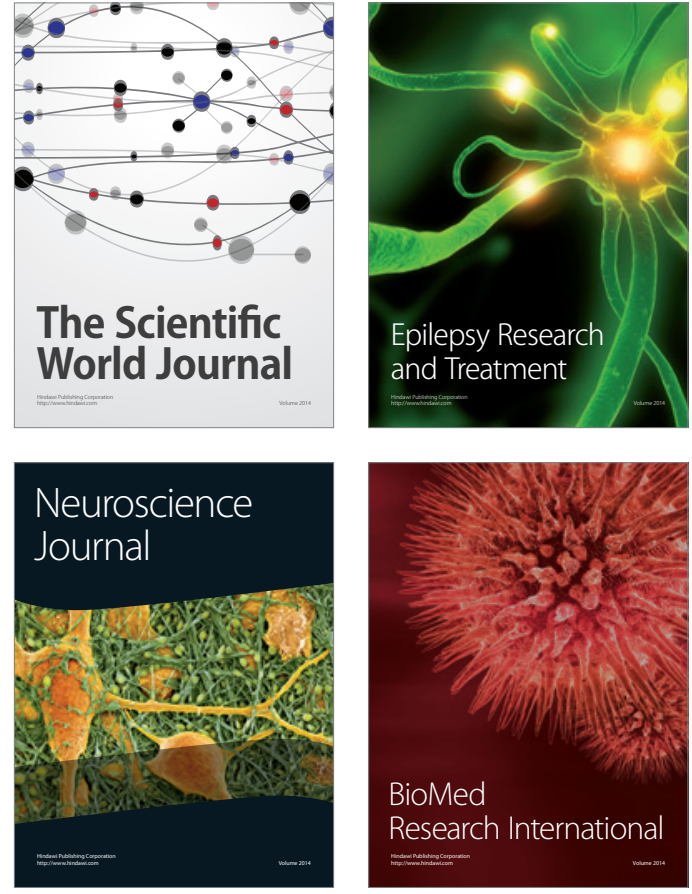

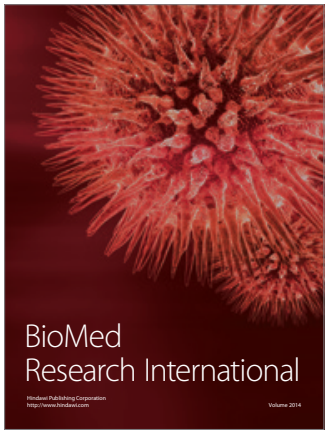

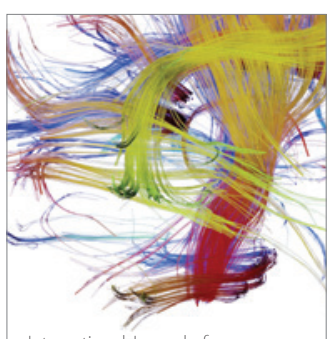

Brain Science

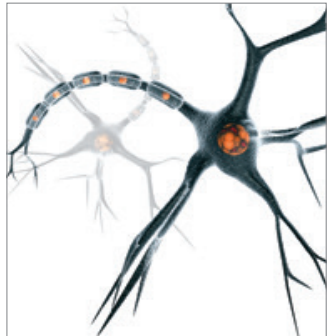

Neural Plasticity
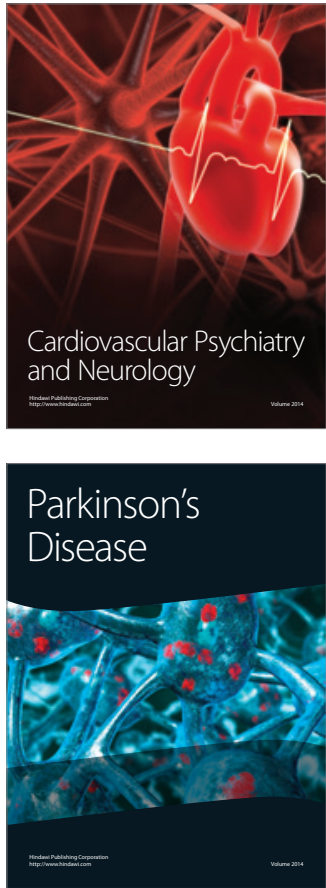